\title{
El humor después del humor: conceptos en torno a Edén de Pablo Holmberg
}

\author{
The humor after of the humor: concepts around Pablo Holberg's \\ Eden
}

Pablo Turnes ${ }^{1}$

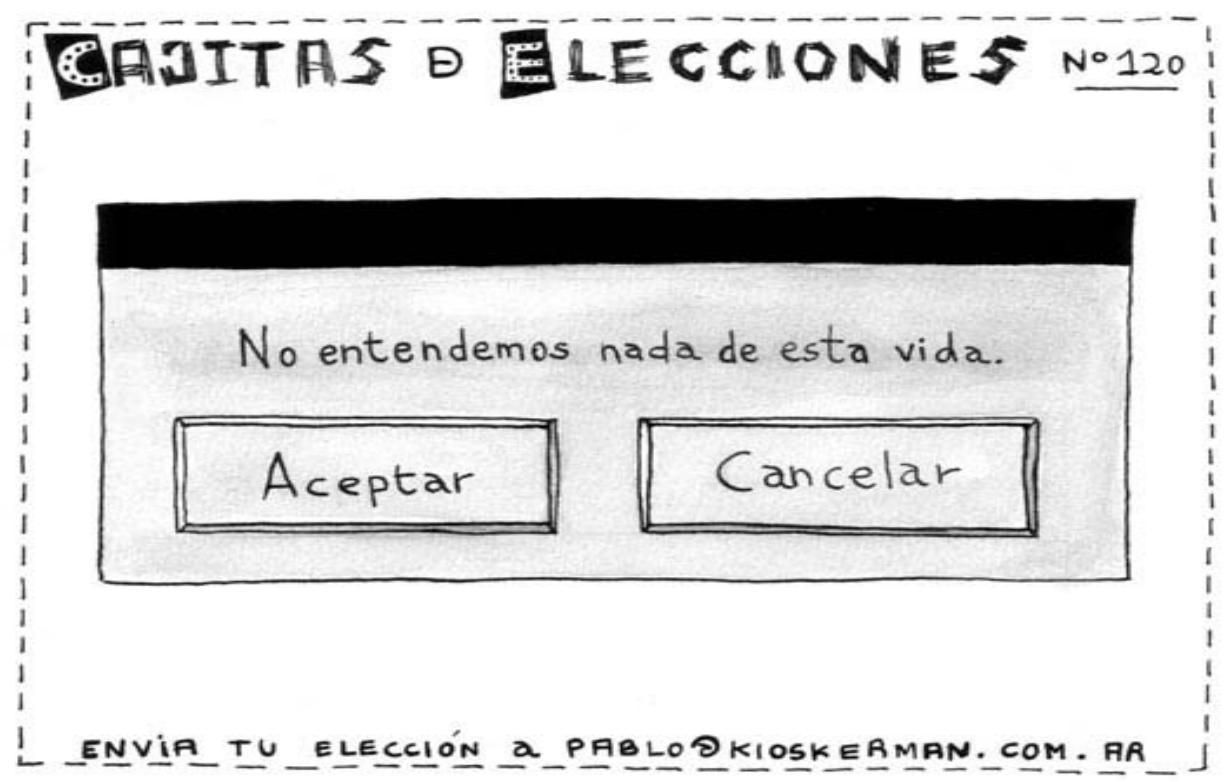

RESUMEN

A comienzos del siglo XXI la producción historietística argentina ha visto la aparición de nuevos métodos de publicación, promoción y circulación compuestos por una serie de dispositivos cuya compleja relación ha redefinido la figura autoral y también la de un público nuevo. El paso de la internet y el formato digital al libro se consolida como estrategia post-industrial en un contexto de reconstitución de un campo historietístico diverso, donde el humor gráfico como tradición nacional es ejemplo de los cambios producidos.

\footnotetext{
${ }^{1}$ Instituto de Altos Estudios Sociales (IDAES). Universidad Nacional de General San Martín UNSAM - CONICET
} 


\section{ABSTRACT}

At the beginning of 21st century comics production in Argentina have experienced the emergence of new methods of publication, promotion and circulation consisting of a series of devices whose complex relationship has redefined the authorial figureas well as a new reading audience. The passage from the Internet and digital formats to the book has established itself as post-industrial strategy in the context of the reconstitution of a diverse comics field, where the national tradition of humor serves as example of the mentioned changes.

Keywords: Graphic humor. Experimentation. Post-industrial strategies. Author. Reader.

Entre los singulares temas que se repiten en el tiempo, aquellos que generan nuevos interrogantes pero no logran ser respondidos son los que vuelven, una y otra vez como ritornello a recordarnos la pregunta. El humor, sin dudas, es uno de ellos. Sin embargo, su vuelta se hace siempre elusiva, pues al final - como explicaba Henri Bergson -, cuando creíamos haber capturado la ola, su significado se nos escurría entre los dedos dejándonos como premio sólo su espuma, efímera y amarga.

Con el humor gráfico, la cuestión puede ser tanto más decepcionante como prometedora. Nuestra ventaja es contar con límites menos estrechos, pues es un objeto de estudio poco explorado a nivel crítico, y no meramente enciclopédico. Nuestra desventaja es justamente esa: no contar con cierto respaldo anterior que al menos, de forma más o menos equívoca, pudiera señalar alguna coordenada a seguir. La estrategia entonces es invertir la ecuación: el punto de ruptura es el señalamiento de la excepción, no de la norma. ¿Pero a qué hace referencia esto? Desde que Voltaire hiciera una breve referencia a modo de esbozo tipológico de las risas en su Diccionario Filosófico, hasta Sigmund Freud, Henri Bergson y Peter Berger; la cuestión del humor ha estado naturalmente involucrada con la risa, la comicidad y la interacción social. El humor es un mecanismo socialmente instituido y aceptado para redirigir las tensiones de esa misma sociedad de forma restitutiva para el yo (Freud); la risa es colectiva al mostrarnos en un acto mecánico del otro un reflejo de mi propia vulnerabilidad, mitigando así, por un breve instante, el dolor de la muerte (Bergson); el humor tiene su fuente en la incongruencia entre el ser humano y el Universo, y es esta percepción cómica del existir lo que en última instancia le otorga al humor una capacidad redentora (BERGER, 1999; BERGSON, 2003; FREUD, 2004; FREUD, 1979). Todas estas fórmulas nos hablan de la necesidad que cada sociedad ha tenido siempre, durante su existencia, la necesidad del humor como forma de aliviar tensiones, crear o reforzar lazos, y en última instancia entender la vida, incluso hasta el punto de transformarla, al proponer al humor y la risa como verdadero ejercicio vital y ético. Pero la idea de un humor que no implique de manera 
directa y explícita una interacción cómica, es decir básicamente una dinámica oral entre enunciador y receptor, no ha sido debidamente profundizada "El humor gráfico no puede no ser diferente del oral porque su yo herido no tiene voz, no muestra su cuerpo ni su rostro y hasta puede no decir su nombre". (STEIMBERG, 2001, p. 4).

Figura 1 - Manzana
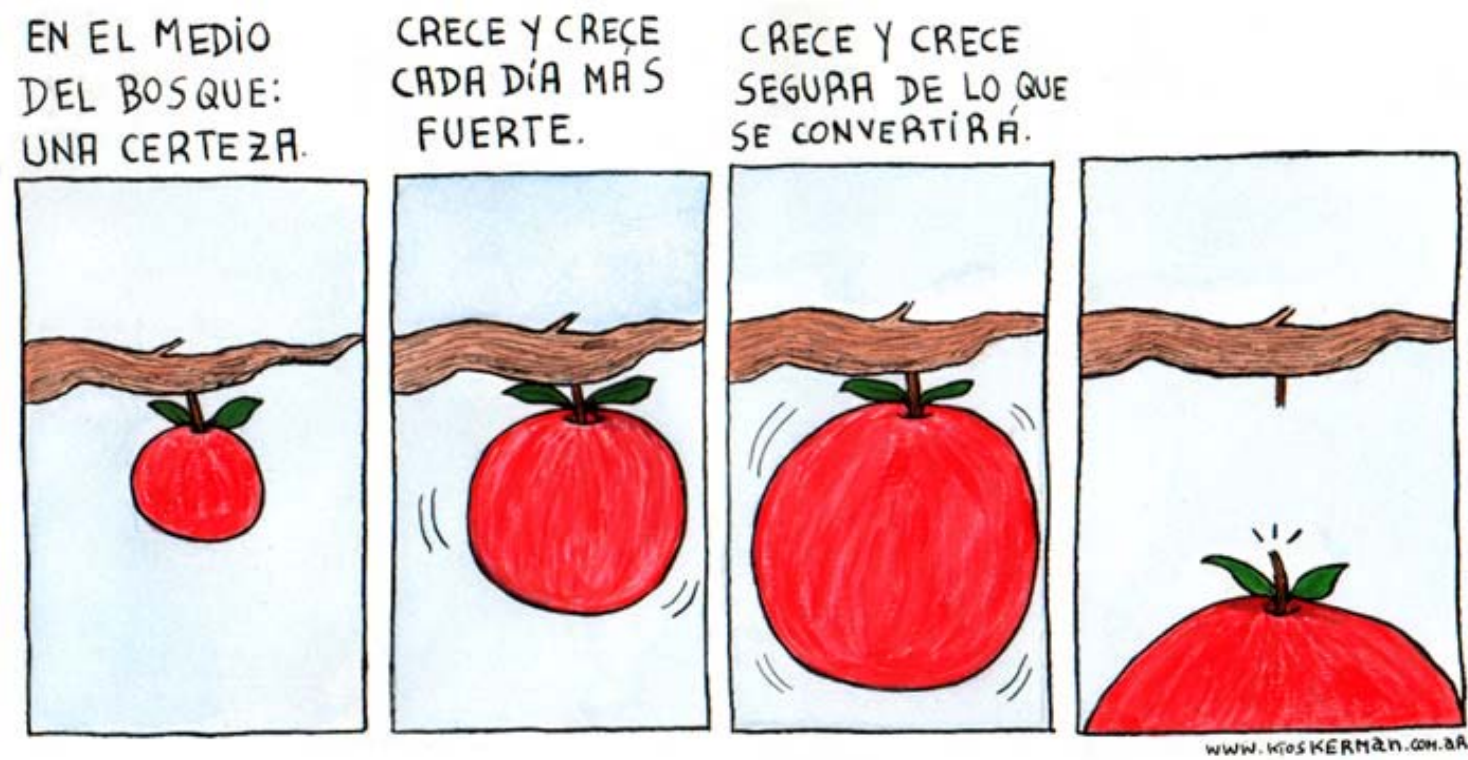

Fonte: Kioskerman (2011)

Esta particularidad en apariencia un tanto angustiosa, ya que implica una renuncia a la dinámica humorística socialmente instituida - y por lo tanto, efectiva merced a esa dinámica -; nos enfrenta a la necesidad de plantear la cuestión en otros términos. Volviendo a Steimberg y su pregunta:

¿Será posible, para que pueda hablarse de "humor gráfico", o cinematográfico, o televisivo -superando la generalización que convierte en "humor" toda comicidad mediática- extrapolar a escenas comunicacionales no únicamente verbales, y no únicamente interindividuales, el dispositivo de descarga de tensión implicado en la secuencia exposición de la carencia -superación por el rasgo de humor? (STEIMBERG, 2001, p. 4) 

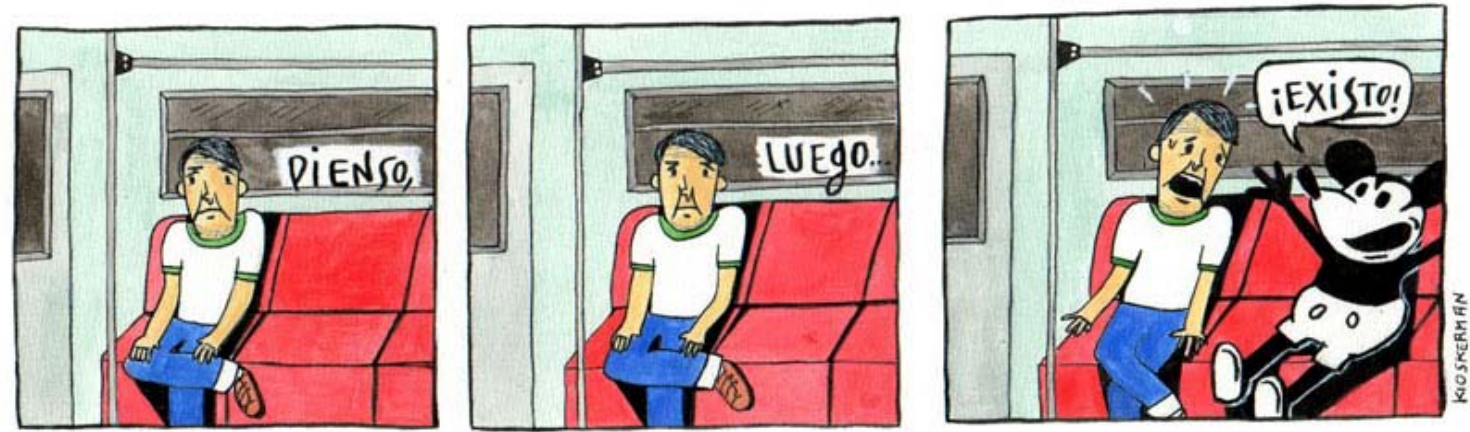

Fonte: Kioskerman (2011)

Steimberg señala que la anomalía del humor gráfico consiste básicamente en un efecto de despersonalización; es decir allí donde había un enunciador presente y explícito, ahora hay una voz enunciativa no-presente que debe ser completada por el receptor a fin de no sólo hacer posible el chiste o la comicidad sino el humor mismo. El resultado es sin dudas particular, ya que su sentido debe filtrarse a través de una serie de relaciones intertextuales que a su vez modifican la trama de ese diálogo invisible y exhiben la materialidad del objeto humorístico. Esta relación conflictiva por la que el humor es enunciado y recibido y al mismo tiempo intervenido por múltiples voces intertextuales pueden resumirse en cuatro factores no excluyentes y a menudo coexistentes: a) su condición no presencial; b) la presencia simultánea de otros textos de la publicación con los que el humor interactúa y dialoga; c) el carácter institucional de la enunciación dado por el soporte y su contexto (es decir, la revista, el periódico, etc.); d) cierta percepción mecánica del enunciador-operador dada por la cotidianeidad repetitiva que tiende a dar por supuesto y previsible la presencia del humor gráfico y su función social en las publicaciones de consumo masivo.

Teniendo esto en cuenta, la diferencia entre la comicidad oral y el humor gráfico estaría dada por lo siguiente: en el primer caso - el más estudiado - el enunciador es una figura tácita, el análisis se dirige directamente a lo dicho, a la revelación de una carencia a la que se le hace frente por la vía explícita del humor; en el segundo caso el carácter social e individual del enunciador debe filtrarse de alguna manera entre esas redes de poder despersonalizador para asumirse como autor social, dado que ese Yo triunfante y restaurado por haber podido superar la carencia que originó la estrategia cómica no puede hacerse presente en el humor gráfico porque la vuelta al enunciador está cancelada desde un principio al no haber un sujeto explícito del cual surge y al 
cual vuelve la experiencia cómica. La experiencia social del humor es a su vez una de resistencia dada por el contrato entre autor y lector, voces que se encuentran y se dan sentido en ese entremedio intertextual, formas de lectura autónomas y al mismo tiempo social y materialmente determinadas por su soporte.

[] para que haya humor en un espacio de comunicación no conversacional, como el del humor gráfico, es necesario que se agregue otra condición: que sea un autor más que individual -que por lo tanto resista la despersonalización del medio- el que transite el pasaje entre caída y distanciamiento humorístico. Y esto ocurre cuando la carencia que está en el planteo inicial del gesto de humor aparece asumida por una imagen de autor que se confunde, enunciativamente, con un segmento sociocultural definido, que siempre es estilístico (se entiende en este caso "estilo", genéricamente, como una manera de hacer grupal, registrable tanto en una determinada asunción de la moda como en un modo de intercambiar información o de sufrir y comentar los problemas políticos). Ese segmento implicado en el efecto enunciativo puede coincidir tanto con una franja etaria como con un sector profesional, una corriente político-partidaria o un "partido" artístico o literario; pero para que esa implicación se produzca será necesario que, efectivamente, del producto humorístico surja una imagen de autor que a la vez represente y sea representado por el segmento-sujeto del drama visual. (STEIMBERG, 2001, p. 6)

Figura 3 - Aulas
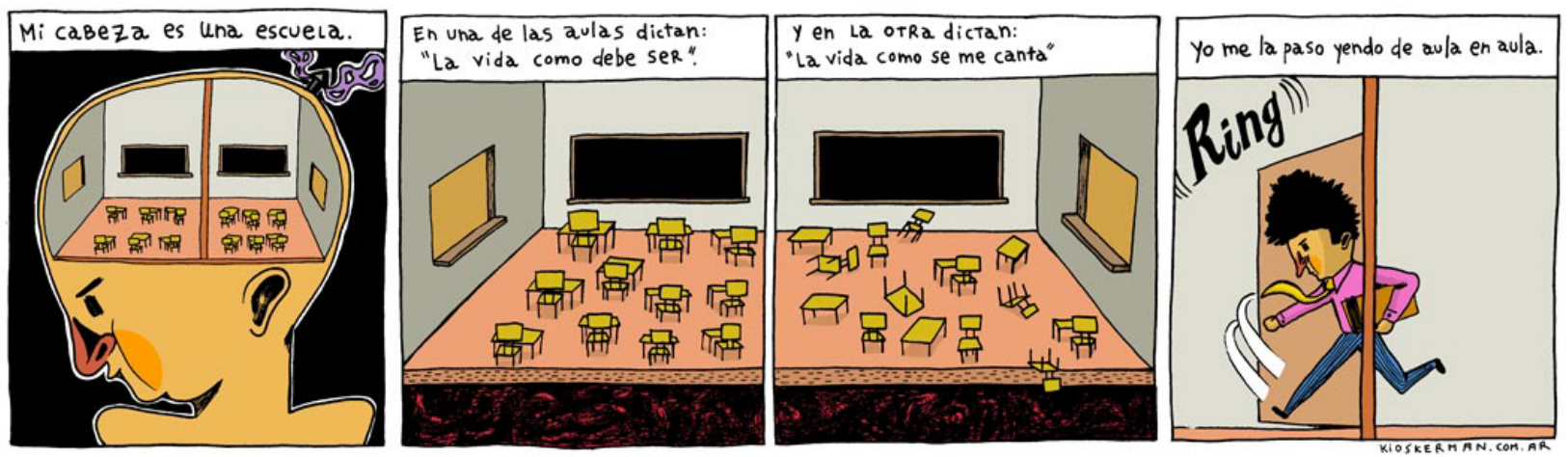

Fonte: Kioskerman (2011) 
Steimberg distingue dos estrategias del humor gráfico para definirlo históricamente: la sátira/pastiche y el esquematismo/experimentación. El primer binomio hace hincapié en el carácter metatextual del humor gráfico que toma la sátira y el pastiche - es decir, la inclusión de elementos externos en principio carentes de toda comicidad -. Esta es una estrategia que posibilita la creación de cierto espacio autónomo que constituye la experiencia humorística, incluso cuando el autor está alineado con la matriz editorial que soporta su obra. El segundo binomio está más cercano a la obra que tendremos a bien analizar. Steimberg cita a Gombrich y sus tratados sobre la caricatura cuando define una propiedad del dibujo/caricatura, más bien un momento de ese arte donde el lenguaje no deviene especular ni mimético, sino que aún con base en cierto nivel de representación del mundo externo, es el trazo del autor el que define un tipo de experimentación que ayuda a construir una signatura particular y diferenciada de la obra y por lo tanto, de quien la compone en un primer momento (STEIMBERG, 2001, p. 7). No se trata de una proyección lineal donde se parte de la experimentación y a medida que crece la masividad de la circulación del producto esa misma experimentación decanta en esquematismo, como para satisfacer a un público más amplio y por lo tanto menos reconocido en sus singularidades - al mismo tiempo que se despliega un abanico de autores diferentes entre sí, pero también una lógica fordista al estilo de algunas tiras norteamericanas publicadas durante años incluso después de la renuncia o muerte de sus creadores que siguieron siendo realizadas por imitadores del estilo, o incluso con estilos diferentes pero con el título y el nombre del creador como marca indeleble -. Este es justamente el punto: hay experimentación y esquematización. El juego conflictivo de la creación dentro de la maquinaria industrial ha alcanzado más visibilidad desde el humor gráfico en oposición a la invisibilización autoral de otras producciones gráficas como las historietas de género. Estaríamos entonces, según Steimberg, ante tres nuevos principios de este nuevo humor: a) autonomización relativa de elementos y dispositivos constructivos "micro", no molares; b) crecimiento del metadiscurso interno; c) crecimiento del pastiche y la parodia no satírica.

Como en todo momento de cambio estilístico, en la mayor parte de los casos se trata de acentuaciones, y no de oposiciones de claro perfil; pero su reconocimiento es necesario si se trata de indagar el estado actual de algunos ejes de significación en géneros que tradicionalmente han hecho la crónica crítica de nuestra sociedad y que hoy, como si el periplo iniciado con los dibujos de Daumier se hubiera cumplido y estuviera recomenzando en otra instancia, nos hacen saber que están probando otra vez efectos de sentido en tramas complejas, en gestos opacos, en pruebas de materiales y técnicas, en la vigilancia sobre los dispositivos del propio discurso. (STEIMBERG, 2001, p. 10) 
Figura 4 - Narrador
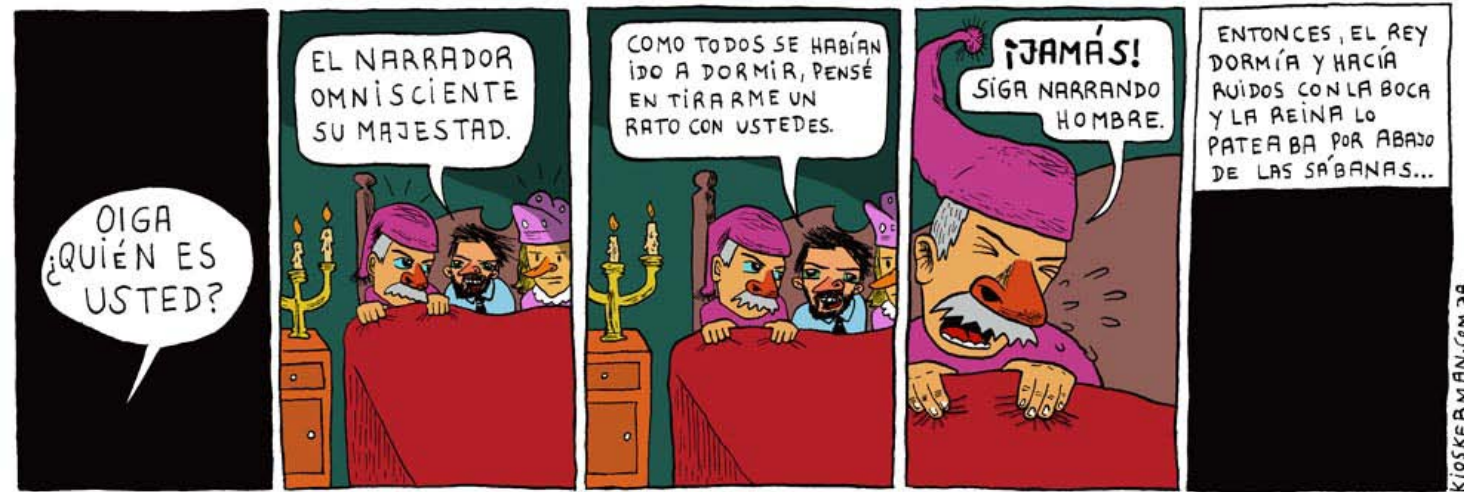

Fonte: Kioskerman (2011)

Una época transicional donde han cambiado los términos exige también nuevos conceptos. ¿Pero dónde buscarlos? Desde el artículo de Steimberg hasta la aparición en libro de Edén ha pasado casi una década. Sin embargo, los cambios hacia el interior del decenio se han sucedido de forma vertiginosa, tanto que recién ahora podemos comenzar a tomar cierta distancia y conciencia de ese veloz devenir. Federico Reggiani ha señalado este cambio que podríamos definir como el desajuste de un sentir de época pretérito y la búsqueda de una nueva sintonía. Tal diagnóstico es inseparable de su soporte material. Si el género del humor gráfico estaba atado al formato tira, es en cierta decadencia o abandono de la dinámica tradicional de esa misma forma donde el cambio es más perceptible

[ ] lo que ha sido alterado de modo evidente es la necesidad de una de esas construcciones sorprendentes -y graciosas- a efectos de justificar el género "tira". No es necesario que se construya una tensión o una ruptura del sentido común, ni se ata la tira a su eficacia [] Y está relacionado con el hecho de que los diversos modos de la narrativa gráfica -el humor, la historieta- han conquistado una autonomía, muy relativa pero evidente. Y con esa autonomía, claro, vienen las oportunidades. (REGGIANI, 2009).

Reggiani admite cierta perplejidad ante las breves iluminaciones que surgen de obras difíciles de categorizar como Edén. Antes que nada la perplejidad está directamente relacionada con ese desajuste previamente mencionado, es decir, la sintonía es otra. Sin embargo, la lectura pareciera aún estar buscando el remate, el gag, en concreto, el chiste. Y es esta forma de comicidad la que ha quedado desactualizada porque sigue atada a un pasado donde la norma era la masificación, tanto para el lector como para el autor. La diferencia estriba en que, mientras que cierta firma de autor debía superar esa despersonalización señalada por Steimberg por entre las grietas del mecanismo de reproductibilidad industrial para así transmitir cierta singularidad, 
ahora nos encontramos frente al formato libro donde la presencia de un autor es explícita pero dentro de los mismos términos de un humor no verbal. Es decir, se ha cancelado esa intertextualidad de los medios masivos impresos para pasar a una forma autónoma de lenguaje gráfico, donde ya no opera la efectividad del remate sino más bien la explicitación de la autonomía más o menos relativa heredada de ese lenguaje anterior pero ubicado en la resignificación de un dispositivo. Se trata ni más ni menos que de un entrecruzamiento: el dispositivo literario por excelencia - el libro -; el dispositivo humorístico gráfico por excelencia la tira periódica -. Incluso se pueden verificar ciertas prácticas arcaicas así mismas resignificadas por las redes inmateriales de los dispositivos comunicacionales, principalmente la Internet: la lectura del scrolling remite a una lectura anterior a la imprenta; la entrega de pauta periódica diaria, semanal, mensual, etc. - de tiras o historietas que pueden ser o no recopiladas remite a las prácticas de literatura folletinesca del siglo XIX. La relación no es, obsta aclararlo, directa, sino que sirve más bien como resumen del diagnóstico de una época transicional a la cual le corresponde un cambio de público y de la percepción y la relación de ese público con los nuevos/viejos soportes. Estamos, entonces, ante nuevas formas de lectura y por lo tanto, nuevas formas de producir sentido:

\begin{abstract}
[] los contenidos cada vez más prescinden de los contenedores y el lector del diario, el que lo compra en el kiosco, es el lector minoritario de la tira, el que muy probablemente ni la lee o la detesta, y las tiras van creciendo solas y de manera lateral al medio, granjeando más popularidad en Internet que en la prensa. Y esos lectores que buscan especialmente a un autor y a veces ni saben en qué medio pública, establecen relaciones de complicidad que permiten abandonar la necesidad de un efecto directo en cada entrega. (REGGIANI, 2009b).
\end{abstract}

Figura 5 - Vigilia

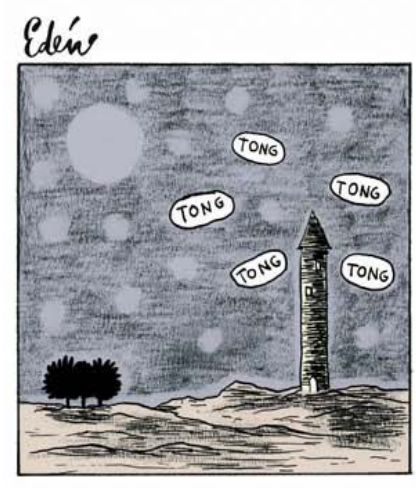

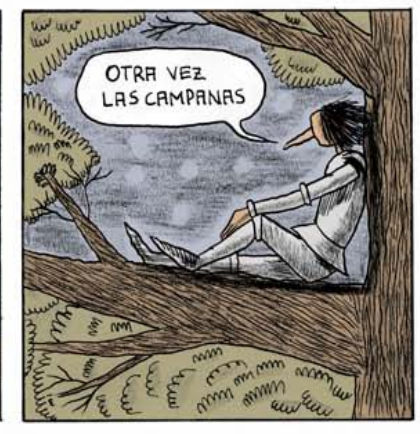

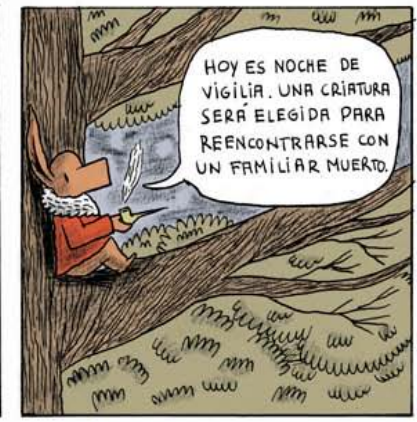

Fonte: Kioskerman (2011)

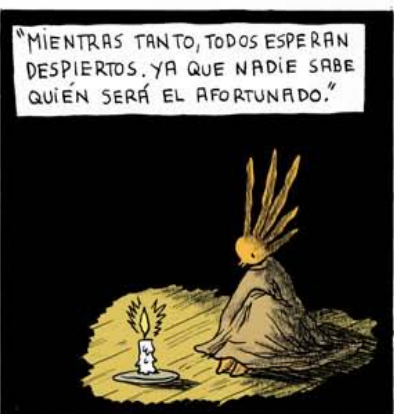

KIOSKERMAN. COM.AR 
Hemos hablado del abandono de cierta comicidad atada al chiste - o al efecto del remate -; de la aparición de nuevas formas de publicación que implican nuevos dispositivos y maneras de contacto con un público no-masivo pero sí multitudinario - en el sentido spinoziano, es decir en un ser/hacer con los otros incluso en las prácticas virtuales -; del sujeto autor aún despersonalizado en el grafismo pero presente más que nunca y de manera explícita en su enunciación como tal; de un desajuste en la producción del sentido atada a prácticas y dispositivos hoy considerados tradicionales pero aún presentes, fusionados con prácticas innovadoras; de la creciente autonomización de las formas de lenguaje gráfico. Para seguir construyendo el camino de nuestra exploración, debemos involucrarnos con la obra que da sentido a estas - aún precarias - reflexiones: ¿de qué se trata, entonces, Edén de Pablo Holmberg? El propio autor ha reflexionado al respecto:

El tema principal es la creación de un mundo. Lo que realmente me interesa mucho son los mundos creados. Pueden ser fantásticos o no, eso me es indistinto. Yo creo que el autor asume el papel de "creador" cuando te transporta al mundo que inventó y ese mundo te resulta verosímil. Perderme en esos mundos es lo que más me gusta de que me cuenten historias. Yo quise replicar eso. Retomar un poco el concepto de tira que tenía Winsor McCay, donde los personajes y su desarrollo como tales, no tienen tanta importancia como el descubrimiento del mundo. Quiero que la persona que lea Edén siempre descubra un rincón nuevo de ese lugar, no que sepa de antemano como va a reaccionar un personaje ante tal situación. El nombre también marca la temática; el Edén es un lugar idílico. Pero no porque sea todo lindo (también pasan cosas feas, como en la vida) sino porque puedo inventar mi propio mundo. (HOLMBERG, 2007).

En otra entrevista:

Edén [] es el caos de mi mente representado en un espacio visual concreto, que luego vuelve a ser caos, en otra mente, cuando alguien lo lee. Al mismo tiempo, no siempre lo sé. Ya que, si tengo suerte, me supera y solo lo siento, sin entenderlo demasiado" [ ] "El mundo es el protagonista de Edén. Es una tira de "no-personaje". Y el mundo es el caos de mi mente reflejado en un espacio. Por lo cual, en realidad, el protagonista es mi ensalada mental. Mis contradicciones, mis deseos, mis miedos, mis esperanzas". (JIMÉNEZ, 2011) ${ }^{2}$

El recorrido de Pablo Holmberg/Kioskerman comienza en 2004 cuando publica su tira $E l$ Señor del Kiosco ${ }^{3}$ a través de un sistema innovador que había comenzado a expandirse desde el 2001, cuando a la realidad editorial prácticamente inexistente en la Argentina se le había sumado la devaluación de la moneda lo cual había encarecido los precios del papel de manera importante:

\footnotetext{
${ }^{2}$ Entrevista a Pablo Holmberg publicada en RTVE.es (http://www.rtve.es/), 08/02/2011.

${ }^{3}$ Todas las tiras publicadas correspondientes tanto a El Señor de el Kiosco como a Edén pueden encontrarse en el sitio de Kioskerman (http://www.kioskerman.com.ar).
} 
ese sistema era Internet. Pero a diferencia de otras páginas el sistema era el siguiente: Kioskerman enviaba la tira por correo electrónico, una vez que el lector interesado hubiera pedido la suscripción a dicha tira. De esta manera se fusionaban la idea de la tira que llega su lector al mismo tiempo que cierto nivel de personalización en el servicio al llegar desde el autor a una casilla particular, sin intermediarios. El éxito del sistema supuso su continuidad por sobre los trabajos publicados en papel por parte del mismo autor en la ya extinta revista Plan $V$ o el fanzine colectivo autopublicado Flasia.

En principio, podemos ver un tratamiento en general distinto de las viñetas - suelen aparecer apaisadas o en mayor número - de lo que se verá en Edén, así como también una mayor influencia de Liniers, a quien Holmberg suele citar como uno de sus referentes directos. Esto es notable en cierto uso de un trasfondo cultural y formativo que permite utilizar referencias que podríamos definir como de alta cultura parodiadas, no tanto a las referencias mismas sino a su uso como alta cultura, es decir el clisé vuelto sobre y contra sí mismo, dando como resultado la comicidad en la revelación de esa máscara de clase que ha atado todo pasado a un saber excepcional y obligatorio.

\section{Figura 6 - Evolución}

INGLRTERRA, 1882, DRRWIN Y SU MONO SE BATEN A DUELO...

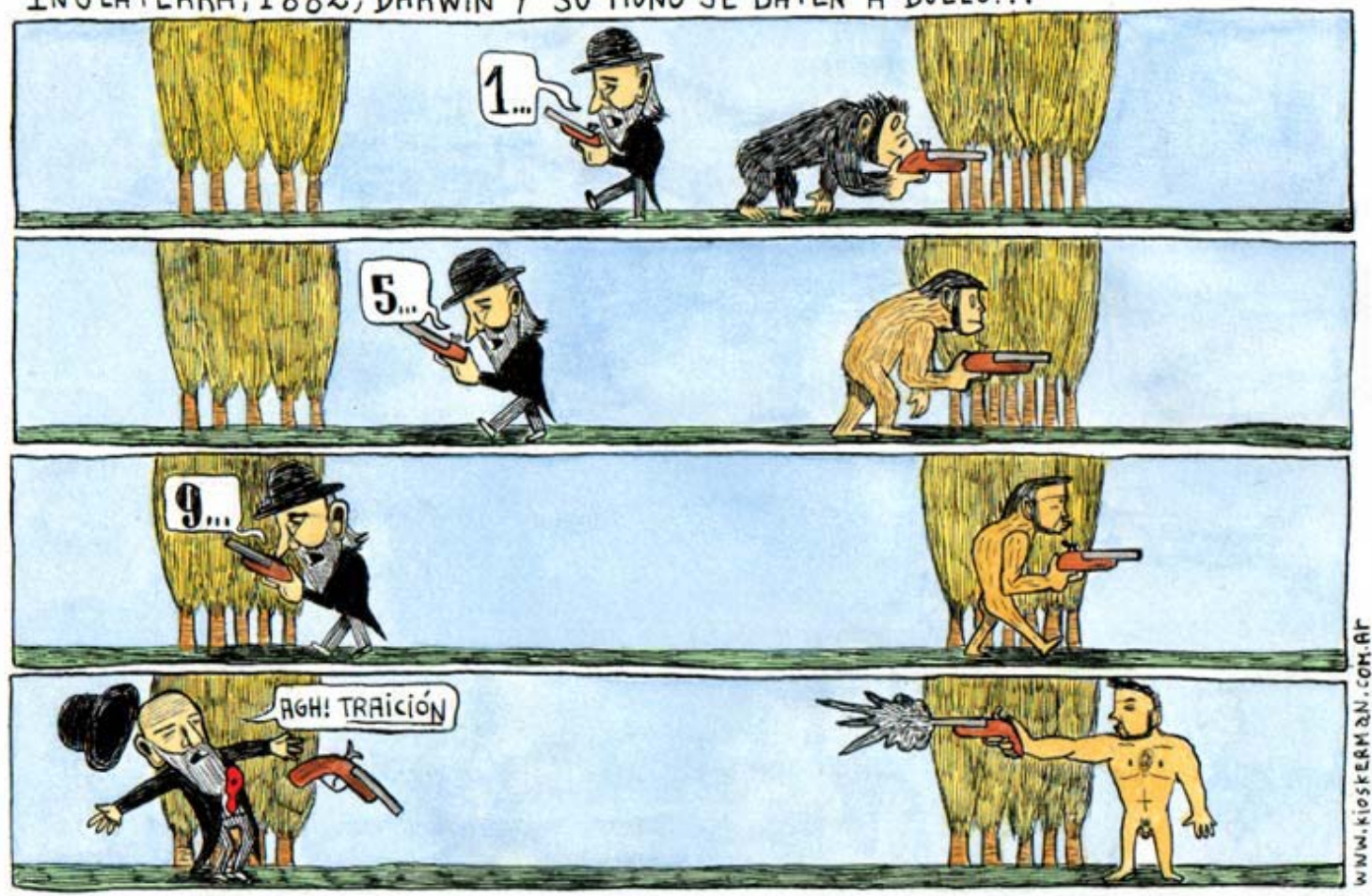

Fonte: Kioskerman (2011) 


\section{Figura 7 - Vincent}
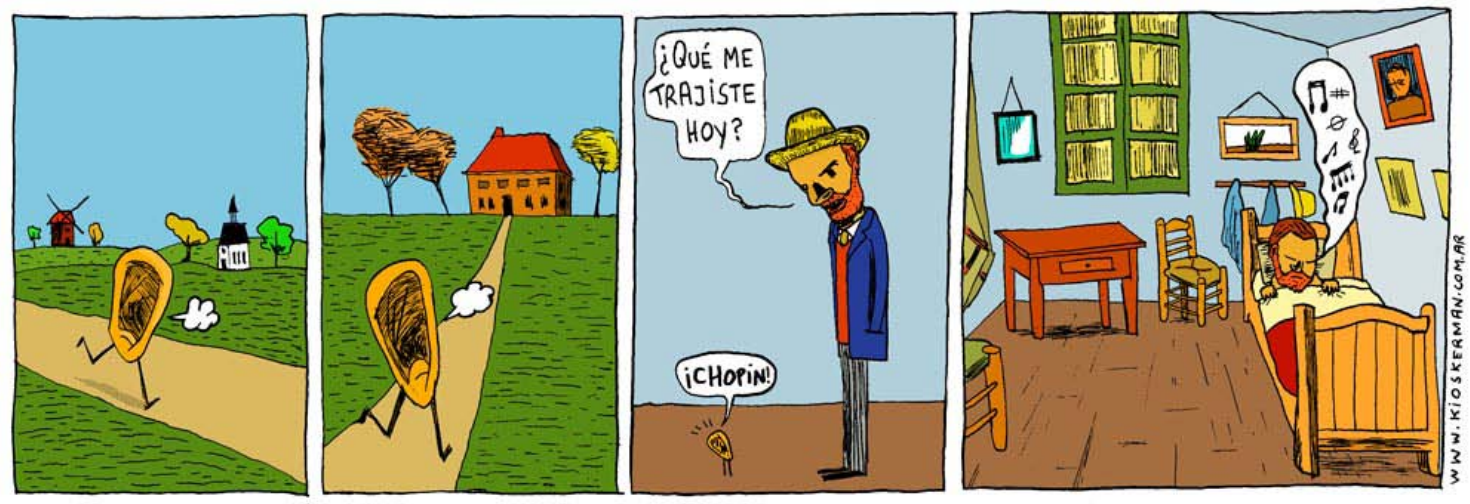

Fonte: Kioskerman (2011)

Esta deconstrucción de un sentido cultural a favor del humor supone ya cierta subversión de un discurso. En contexto, la Argentina post-2001 suponía una revisión de todo lo que hasta entonces constituía un sentido común nacional, entre ellos el mito de la educación como puerta de acceso al bienestar social pero también el del trabajo de humorista gráfico con una larga y respetada tradición. Ninguna de las dos cosas - el capital intelectual, el status quo laboral -, significaba demasiado frente a una realidad que impedía concretar los valores prometidos. En buena parte, la historieta y la gráfica de principios de siglo XXI en Argentina ha hecho propia de manera particular aquel aforismo borgeano que dice que los argentinos pueden considerarse herederos de toda la cultura occidental - e incluso más allá, como lo demuestra la misma fascinación de Borges y otros escritores argentinos con las culturales orientales, particularmente la japonesa -. La obra de Kioskerman/Holmberg es una buena síntesis de esta ecuación, sobre todo a la hora de avanzar sobre una voz propia que ya transita otros caminos que los que cuando comenzara con sus tiras en 2004. 
Figura 8 - Sol
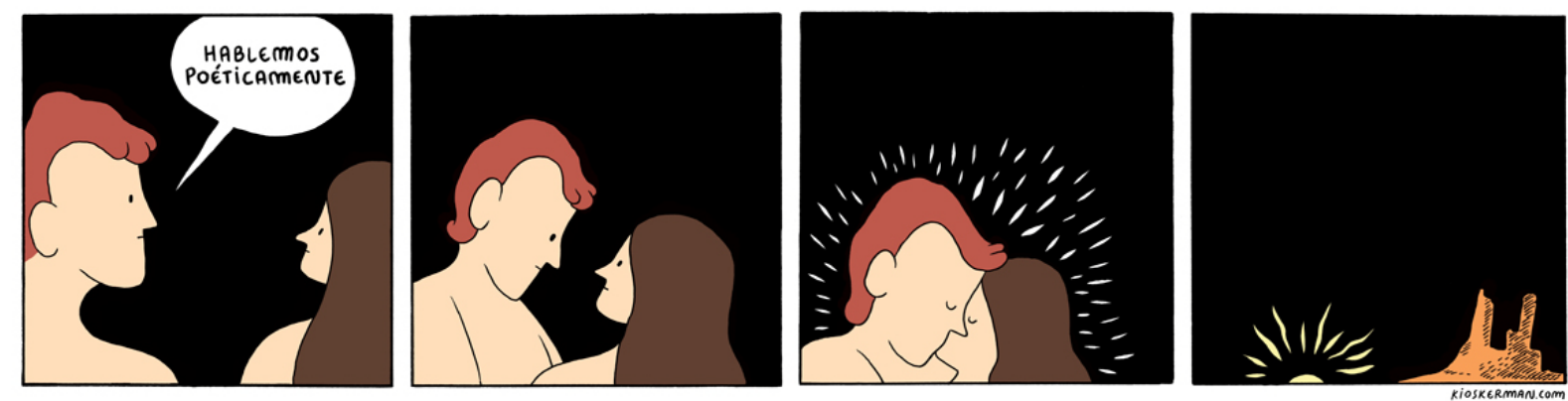

Fonte: Kioskerman (2011)

A partir de 2006, cuando comienza a publicarse Edén, Kioskerman lleva el lenguaje gráfico a extremos interesantes, no siempre parejos. El mismo autor lo deja claro

Creo que hay un espacio gigante en internet para los dibujantes $¿$ no? Yo veo Internet y su funcionamiento como el espacio para el desarrollo de una contracultura. Me interesa mucho como Internet fomenta la aparición de autores. Y cómo uno puede ser testigo de acierto y errores, de crecimiento. (RODRIGUEZ, 2011) ${ }^{4}$

Lo que vemos en Edén, lejos de ser el punto más avanzado de la obra de un autor, es a un autor y su obra en construcción hasta el punto de no poder distinguir claramente entre una cosa y la otra: el autor es su obra, y viceversa. En este sentido, Edén es una obra romántica que incluye cierto arcaísmo en sus aciertos y desaciertos representativos y textuales. Los personajes que se suceden no necesariamente vuelven a aparecer - como si se tratara de un staff regular -, sino que existen en ese presente perpetuo de la tira, una realidad donde el hic et nunc de ese edén pareciera mitigar los efectos de la soledad y de la muerte que si bien se hacen presentes, no son definitivas ni irreversibles. Pero es en la representación de dichos personajes donde hay un sello autoral, ya que parecen éstos sacados de cuentos de hadas, cuyos rasgos pueden ser alternativamente medievales, decimonónicos o mitológicos.

\footnotetext{
${ }^{4}$ Entrevista a Pablo Holmberg publicada en la revista digital Trip (http://revistatrip.uol.com.br), 02/02/2011.
} 
Figura 9 - Ofelia
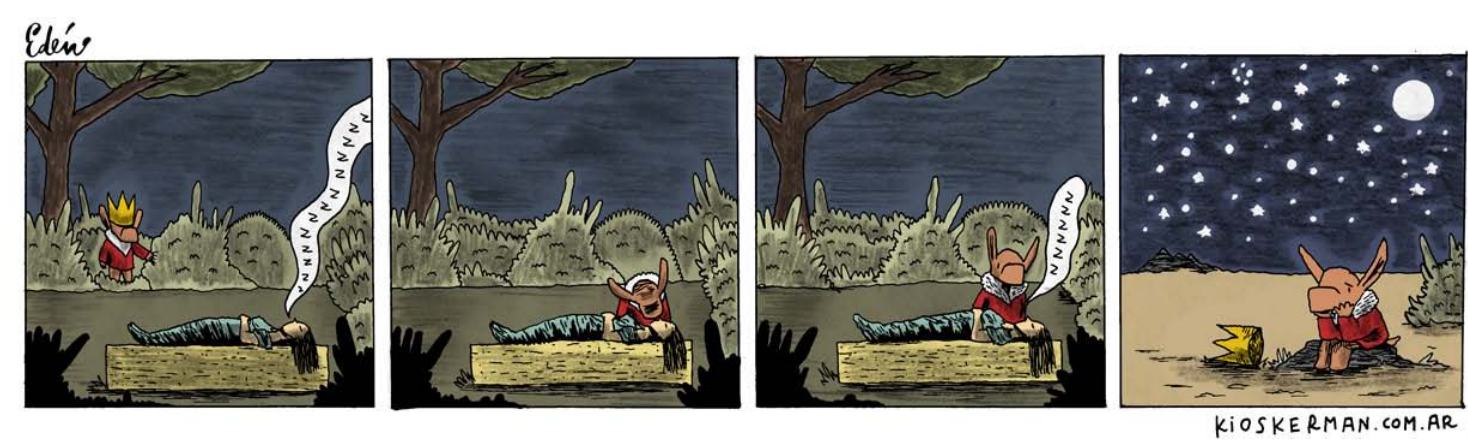

Fonte: Kioskerman (2011)

Esta tira, Ofelia, desde el título mismo hace referencia al personaje mítico, al mismo tiempo que se reflexiona sobre un lugar común del género de cuento de hadas: la princesa que debe ser rescatada de su ensueño por el beso de un príncipe. Pero la realidad de este edén no es necesariamente una causa-efecto prescripta, sino que en su naturaleza las posibilidades son infinitas y los resultados, inesperados. No porque o exista la causa/efecto, sino justamente porque el devenir de ese mundo ya no puede seguir las reglas preestablecidas. En este sentido, Edén habla desde la entropía, desde aquello que se ha perdido y es irrecuperable. Es un mundo de hadas para adultos, aquellos que ya han pasado por la adquisición de un lastre cultural que los ha hecho ganar en conocimiento y perder en sentimientos, en su capacidad afectiva "Decidí hacer una cosa que aparece en Macanudo, pero que Liniers no explota siempre, que es el no-humor" [ ] "me interesa la tira no humorística que lleva a un sentimiento que no es la risa o la alegría". Su camino, destaca, es la poesía. (VENEZUELA, 2010) ${ }^{5}$

He aquí otro de los elementos claves para entender el trabajo de Kioskerman/Holmberg: la musicalidad poética de las tiras. El lenguaje de Edén es a menudo un lenguaje musical que funciona como tal, es decir que no necesariamente dice algo, pero sí transmite.

[] "no estoy tratando de movilizar al espectador a una reacción nerviosa como es al risa o la carcajada, sino que estoy tratando de

\footnotetext{
5 Entrevista a Pablo Holmberg publicada en Cuadritos, periodismo de historieta (http://avcomics.wordpress.com/), 02/05/2010.
} 
llevarlo a otro tipo de emociones que surgen de la secuencia y el ritmo, eso que en la poesía llevan a que vos tengas una experiencia cercana a la belleza". La clave, considera, está justamente en el ritmo y en el tema, que debe ser contundente. "Además, para mi una tira en cuanto tiene muchas palabras empieza a derrapar, no genera el ritmo, y así no genera experiencia poética", analiza. (VENEZUELA, 2010).

Una de las influencias directas de la tira según su autor es Bob Dylan. También se cuentan los mundos oníricos de las primeras historietas masivas de principios del siglo XX como el Little Nemo de Winsor McCay o el Krazy Katz de George Herriman, como también de cierto sentido existencialista y metafísico de Quino y del Peanuts de Charles Schulz y el ya mencionado Liniers como influencia contemporánea. Uno de los cambios claves fue el pasaje a una tira de cuatro viñetas que terminó dando como resultado una fórmula estética, facilitando este pasaje a cierta fluidez efímera, que expresa la potencia de la tira en la tira misma y no en una continuación. Es decir, se valora el efecto - no necesariamente en el remate, si este existe -, antes que en la secuenciación. Esto complejiza más aún el trabajo gráfico, ya que se respeta una fórmula pero al mismo tiempo las relaciones hacia dentro de la tira son complejas y cambiante. Veamos algunos ejemplos:

Figura 10 - Adiós
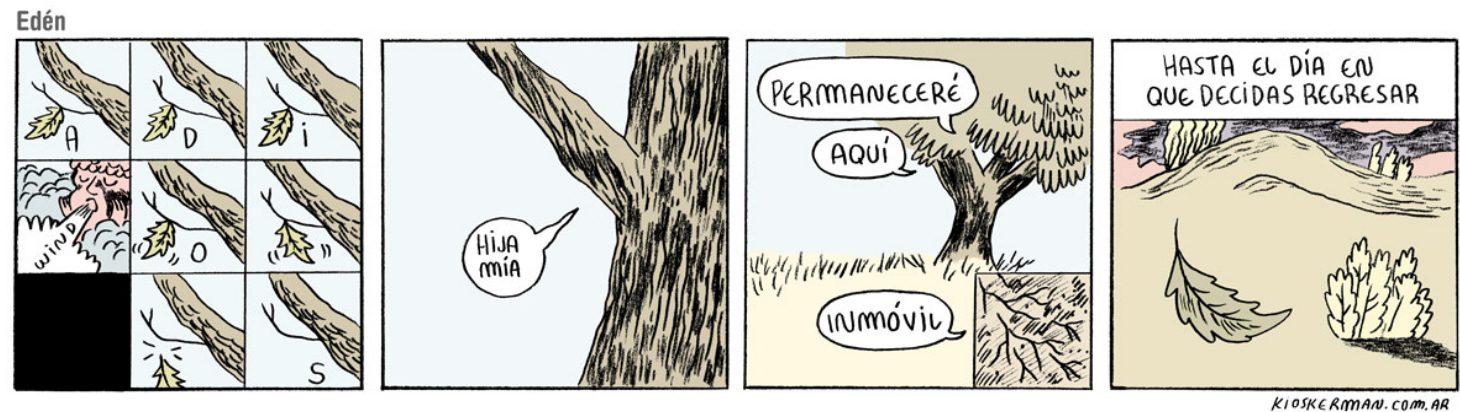

Fonte: Kioskerman (2011) 
Figura 11 - Cosmos
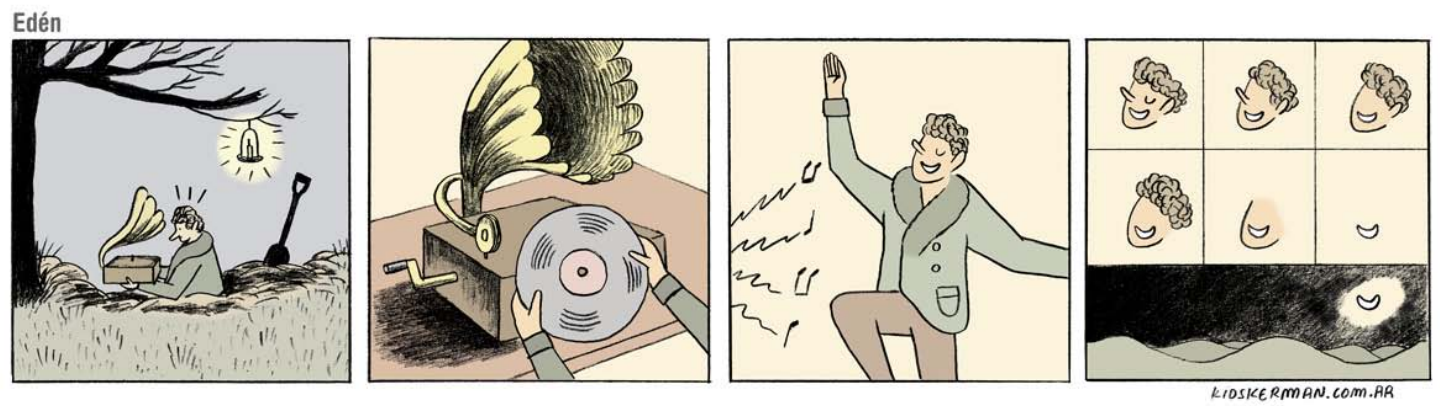

Fonte: Kioskerman (2011)

En la primera tira, Adiós, tenemos, por un lado, texto; y por otro la división interna de las viñetas 1ra y 3ra. El texto ya aparece desde el principio pero de forma particular. Es una viñeta dividida a su vez en 9 viñetas interiores. La secuencia tiende a ralentizar la lectura: se lee la palabra a-d-i-o-s en consonancia con la hoja que cae del árbol. La cuarta mini-viñeta es la representación clásica del viento como Eolo, con las mejillas hinchadas insuflando aire y podemos leer wind, palabra inglesa para viento. ${ }^{6}$ La instalación de la acción se apoya en esta imagen del viento como en la 7ma mini-viñeta, que aparece en negro, un breve fundido-a-negro que suspende la acción por un segundo, para luego retomarla. La experimentación da resultados interesantes. Inténtese una lectura secuenciada de las viñetas 1-4-7, o en la diagonales 1-5-9 o incluso invirtiendo el orden occidental de lectura, 3-5-7.

Figura 12 - El viento

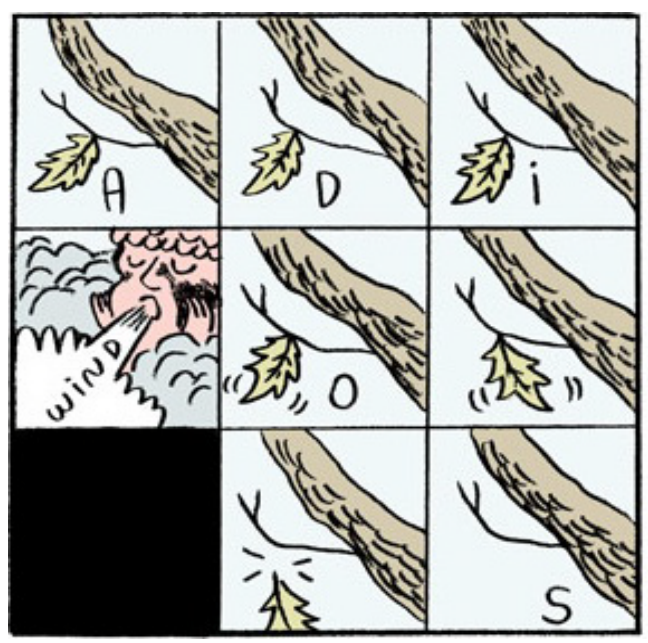

Fonte: Kioskerman (2011)

\footnotetext{
${ }^{6}$ La curiosa elección podría vez esté basada en algún grabado de William Blake, a quien Kioskerman/Holmberg tiene como referencia. Sin embargo, hasta este punto es pura especulación.
} 
En las tres viñetas siguientes, aparece el texto en forma tradicional, es decir en globos de diálogo y cartucho de texto. Sin embargo, aquí también estamos frente a un uso particular del soliloquio del árbol: un ser que no es parlante habla desde su integridad, tanto que en la tercera viñeta aparece una mini-viñeta en el margen inferior derecho a modo de radiografía donde nos habla desde su raíz y dice inmóvil. El texto parece servir más bien a esa experimentación gráfica antes que a enfatizar el carácter inmóvil del árbol, algo que por otro lado resultaría redundante. En la última viñeta el texto ya flota en el viento, y está dirigido a la hoja que se aleja. En esa última viñeta confluyen todos los elementos anteriores: el viento, la hoja y el árbol. Es una certera utilización de los recursos gráfico de la historieta que son desplegados como acción y contracción, haciendo hablar en un medio que no es ni verbal ni sonoro, pero donde la palabra se explicita en su grafismo y no podemos evitar darle voz.

En el segundo caso, la secuencia es aún más extraña. El componente onírico supera el sinsentido inicial - ¿Qué hace un hombre desenterrando un gramófono? - y remata con un recurso literario que juega entre la sinécdoque y el kenning.

Figura 13 - Rostro

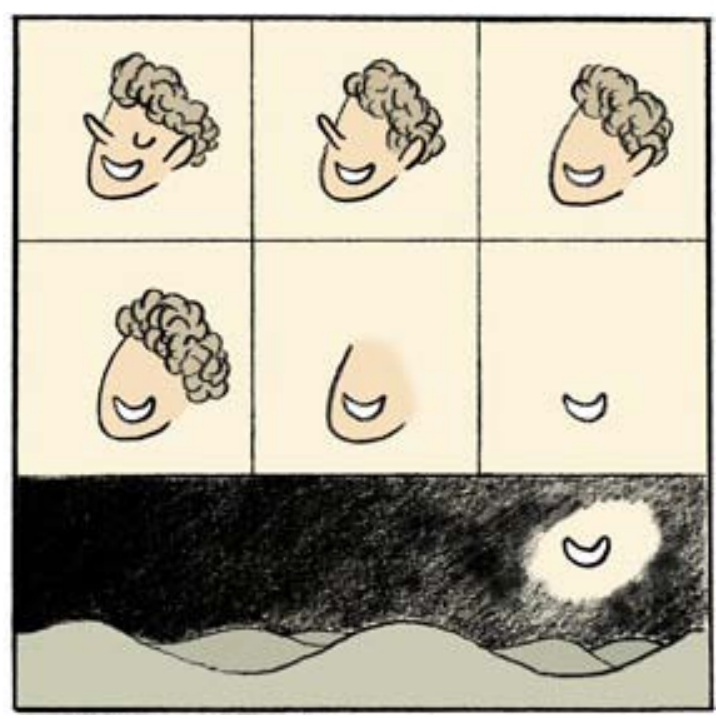

Fonte: Kioskerman (2011)

El cuarto menguante lunar termina completando la secuencia del rostro que se desvanece dejando sólo una esquemática sonrisa. Nuevamente nos encontramos con una última viñeta con siete viñetas internas, pero esta vez sin texto, aunque podríamos decir que el sonido lo proveen las notas musicales. Este es un buen ejemplo de ese no-humor, entendido como la renuncia a la 
búsqueda del efecto en la risa; se busca antes el efecto poético y tal vez, la sonrisa. En su ritmo y su sentido, está más cerca de juegos literarios y poéticos, aquellos que nos revelan la musicalidad que también existe en el leer; en el sentir de la lectura.

Esto último no lleva a otro interrogante: ¿cómo es entonces la relación entre imagen y palabra en Edén? Es de por sí, e inevitablemente, una relación conflictiva. Pero es desde ese mismo conflicto de donde surge la posibilidad de una lectura gráfica. Esto también está relacionado con el formato, en cómo está pensada la limitación formal desde la que se genera el relato No me gusta mucho el término "humor gráfico" a decir verdad. Me gusta más "comic" a secas y yo incluyo ahí todo lo que se cuente con imágenes y palabras. (HOLMBERG, 2007).

Y también:

Las primeras tiras de Edén, recuerda ante el grabador de Cuadritos, son "plena experimentación" y tienen una influencia "bastante grande y estudiada" de Charles Shulz. "Por eso están hechas en cuatro cuadros, luego me acostumbré a pensar así y se me volvió un mantra internalizado, de narrar en cuatro viñetas", explica. Surgida como "una especie de autoboicot", una ruptura con su trabajo anterior, la tira se fue construyendo a cada domingo, enviada por mail a sus seguidores. (VENEZUELA, 2010)

Por un lado, se renuncia a la categoría humor gráfico a favor de la de comic - aunque ambas son arbitrarias, como toda categoría, también ayudan a definir algo, como toda categoría -. Por otro, la renuncia a un manejo formal que primaba en algunos de los ejemplos anteriormente vistos - correspondientes a su período de El Señor del Kiosco - y un nuevo orden basado en las tiras de Charles M. Schulz pero considerado como mantra internalizado, es decir casi un ejercicio espiritual de ruptura con ese orden anterior ya adquirido y de compromiso con la experimentación gráfica y lingüística. Como se ha mencionado anteriormente, el binomio esquematismo/experimentación sirve como apuntalador de la experiencia gráfica que Kioskerman/Holmberg lleva a cabo en Edén. El uso de la palabra suele ser parte de ese binomio la tira es en sí todo un experimento -, pero sus resultados pueden ser tanto interesantes y desafiantes como dispares: 
Figura 14 - Abuelo
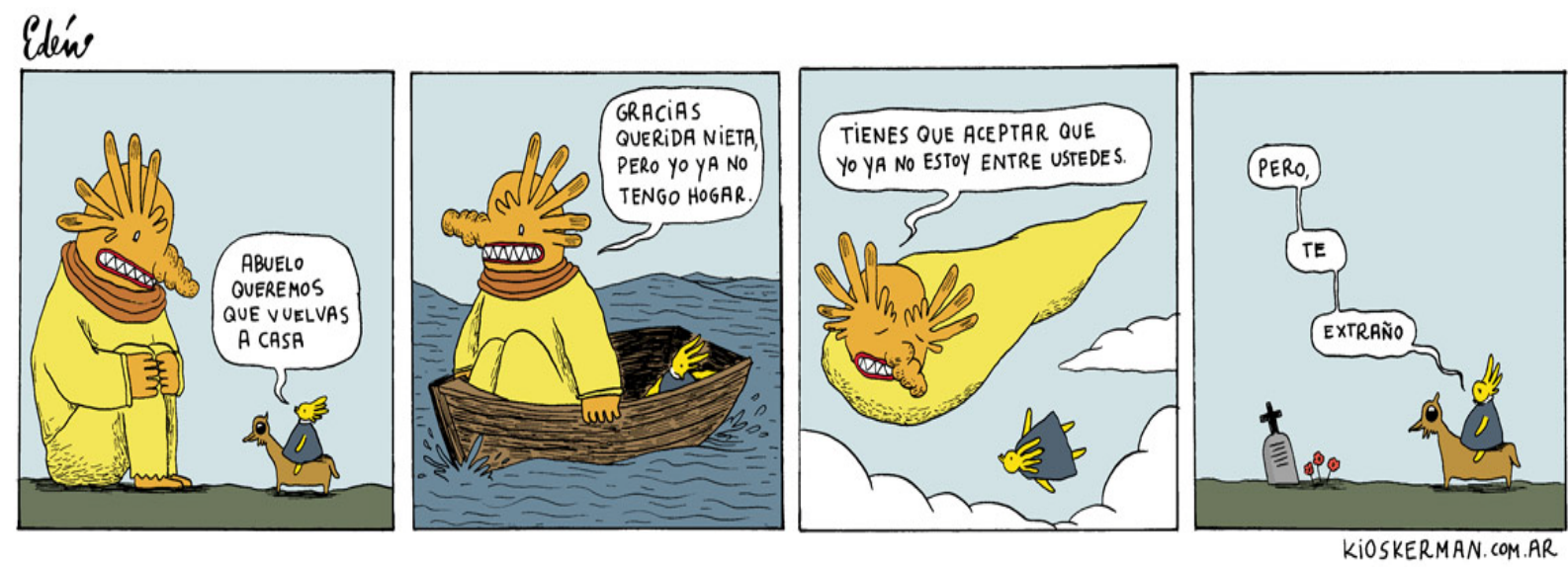

Fonte: Kioskerman (2011)

Figura 15 - Luna
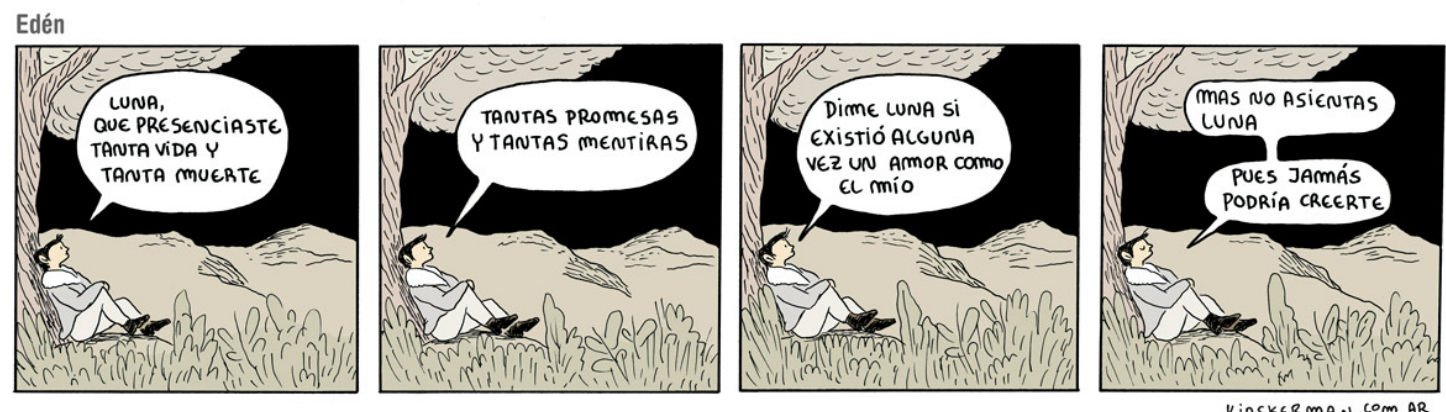

Fonte: Kioskerman (2011)

En el primero, Abuelo, la extrañeza de los personajes y ese mundo que se construye constantemente a su alrededor - tierra, agua, aire -, crean una secuencia extraña y misteriosa. El diálogo se ve enrarecido por ese deambular y mutar de sus enunciadores. Sin embargo, el remate 
sabotea el fluir al interrumpirlo con un golpe bajo, expresado y reforzado con patetismo por el pero/te/extraño de la que pareciera ser una niña. Tal vez el sólo mostrar una tumba hubiese sido ya suficiente, si no es que demasiado. Aquí se invierte el efecto con respecto a las tiras anteriores: el sentido poético es secundario al efecto final y la verbalización que se supone trágica es incongruente por exceso, cuando hubiese convenido la síntesis. Los globos divididos hacen más lenta la lectura como para que no se nos pierda de vista que el final es triste. La palabra revela su torpeza al intentar explicar lo que es intransferible.

En el segundo caso, Luna, el problema es otro. El soliloquio del personaje, quien le habla a una luna fuera de cuadro, resulta excesivo y por eso pretencioso. Ninguna viñeta es igual a la otra, pero su similitud hace que el registro gráfico sea monocorde. Esto lleva la atención al globo de diálogo, que con su contraste blanco/negro llama la atención antes que la paleta de colores oscuros y más bien neutros de la viñeta. El protagonista es el texto, y este no se sostiene por sí mismo. Su efecto poético es errátil y al prescindir de la tensión del dibujo su remate se vuelve ramplón. Es una tira fallida. Esto forma parte del experimento, pero afortunadamente no lo define sino más bien representa algunos riesgos a correr que puede jugar en contra de la calidad del trabajo. La compleja relación entre imagen y palabra que suele parecer oculta y superada en otras formas gráficas, suele ser más visible cuando esas mismas formas mutan y se tornan experimentales y abiertas a nuevos planteos.

Edén existe en una naturaleza percibida como amoral, donde no existe ni Bien ni Mal, sino que existen lo bueno y lo malo, y estos son a su vez relativos:

\section{Figura 16 - Madre}
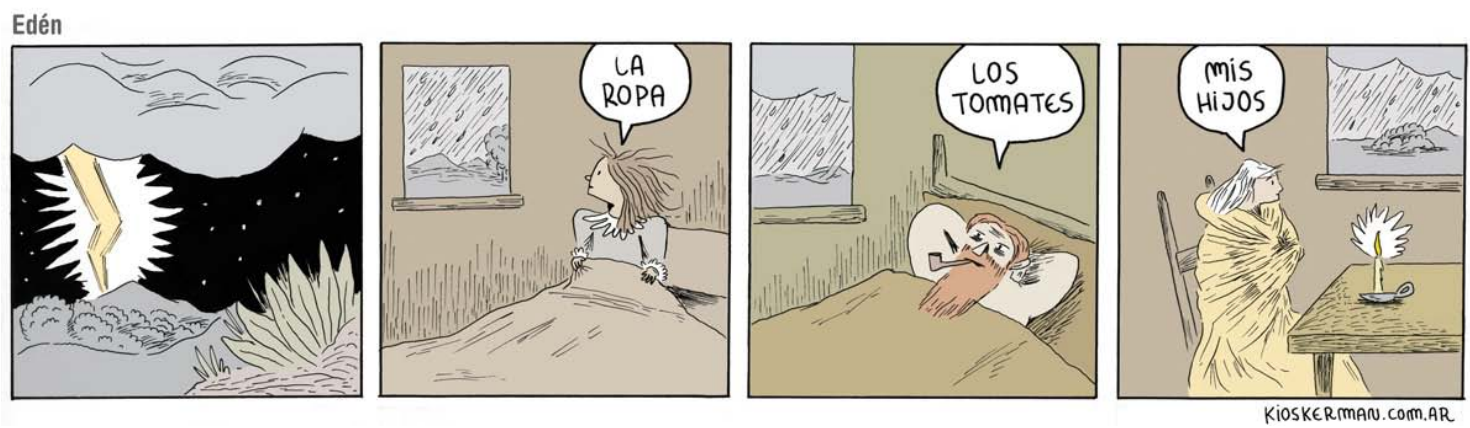

Fonte: Kioskerman (2011) 
Figura 17 - Hongos
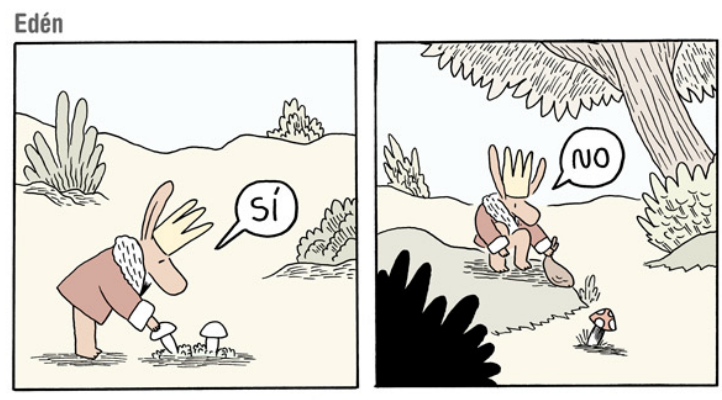

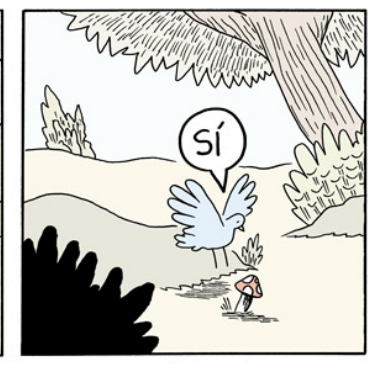

Fonte: Kioskerman (2011)

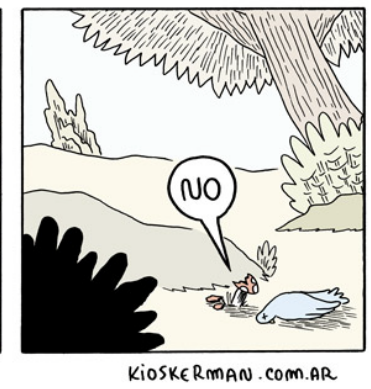

El esquematismo algo romántico de Edén suele ganar fuerza cuando nos da una visión para nada inocente de lo real. En concreto: en este edén también existen la tristeza y la muerte. Ambos casos revisten un carácter spinoziano, la relación entre los cuerpos produce resultados diferentes cada vez. Todo se resuelve por la capacidad de dichos encuentros de sumar o restar potencia. El rayo que anuncia la tormenta que trae la lluvia es bueno para los tomates pero malo para la ropa y aún peor para los hijos lejanos. Ninguno de los personajes puede ser juzgado por comparación con los otros sino en tanto su misma necesidad y su relación con aquello que no se muestra pero pasa a existir al ser nombrado. En la segunda tira, el reiterativo sí/no cambia su sentido al ser enunciado desde diferentes voces con diferentes consecuencias. Nuevamente, los actores no son buenos o malos a priori, esos roles son definidos en el encuentro que tienen con otros cuerpos. En estos casos el uso de la palabra justa, ya sea para nombrar a lo que no está representado pero existe; ya sea definiendo en su fórmula más básica todo un conjunto de posibilidades hacen que la experimentación sea exitosa en fusión con el esquematismo del trazo. Es difícil encontrar ejemplos que intenten otra aproximación fuera de las cuatro viñetas y el uso frecuente del texto. En la recopilación que Editorial Sudamericana publicó bajo el título Edén, de un total de 112 tiras de cuatro viñetas, 99 incluyen texto de algún tipo - diálogo, onomatopeya, metatexto, texto narrativo, etc. -. Sólo dos tiras son a página entera y sólo una contiene lo que podríamos llamar en términos de Steimberg sátira/pastiche, por el uso del collage: 
Figura 18 - Cuervo

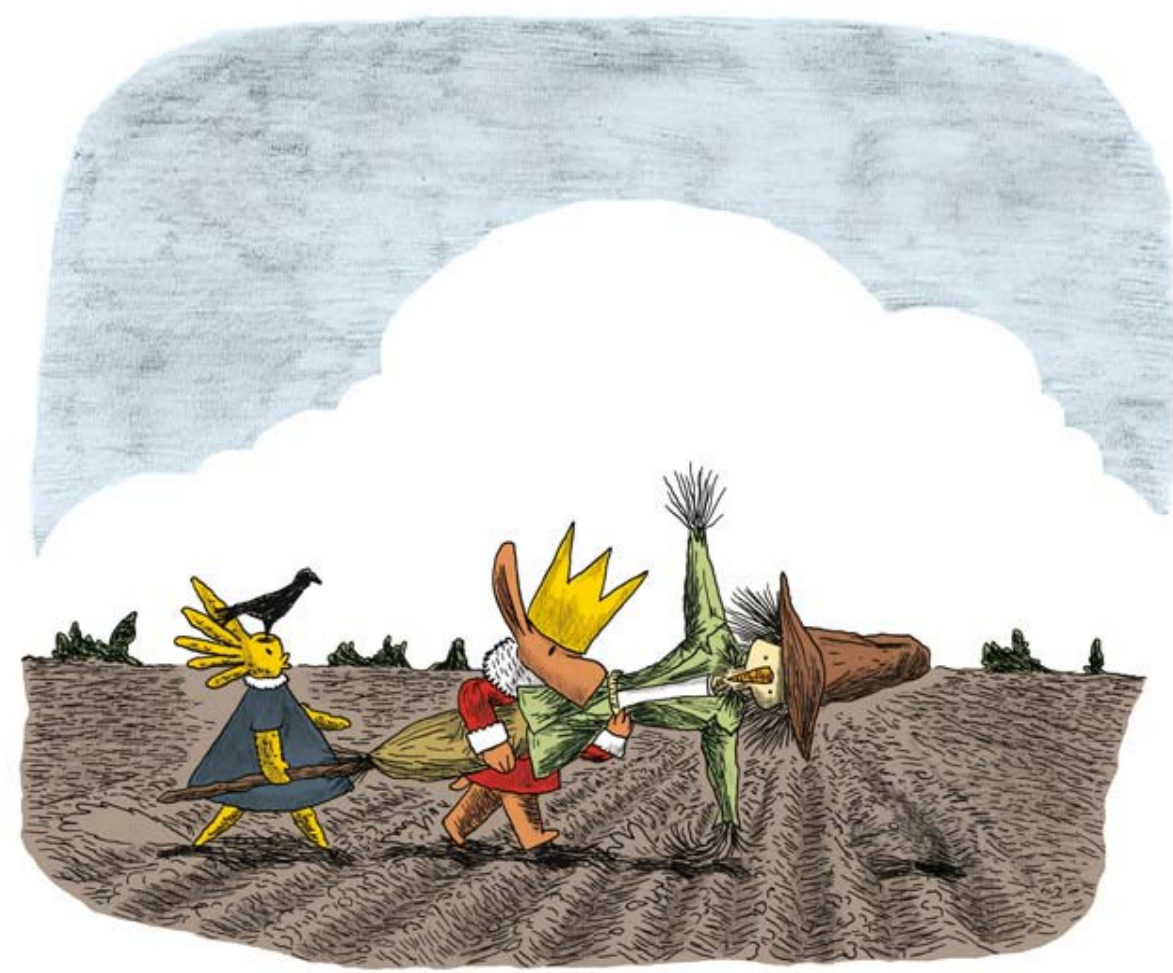

"Tengo la sensación de que esto no va a funcionar."

Fonte: Kioskerman (2011)

Figura 19 - Ciudad
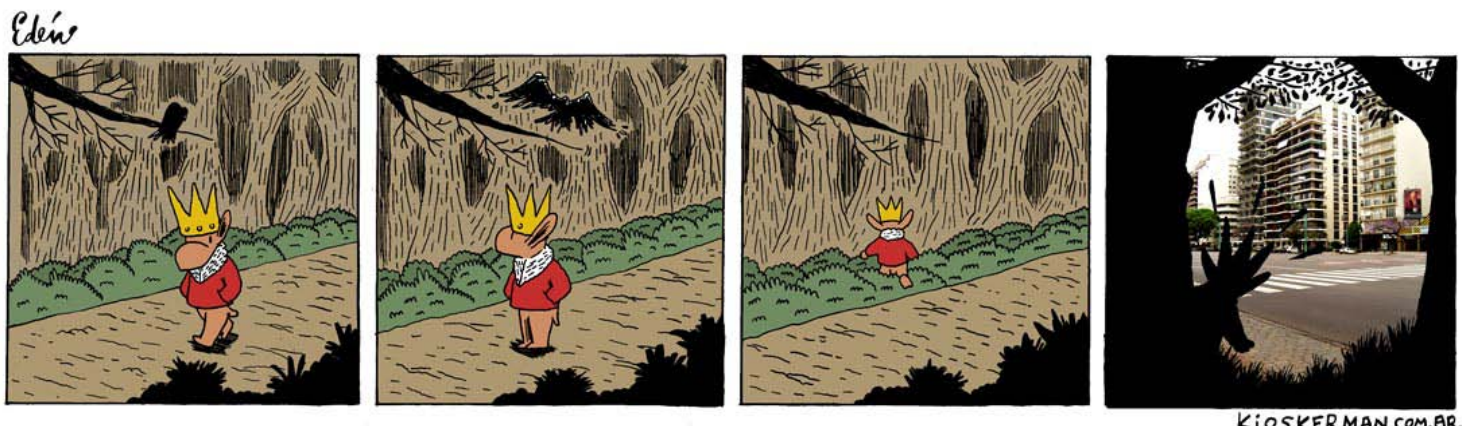

Fonte: Kioskerman (2011) 
El primer caso es interesante, por dos razones en particular: a) el uso del texto hace que no esté claro quién lo enuncia, disparando más de una posibilidad - parece ser el cuervo el enunciador, pero podría ser la niña que vimos en la tira Abuelo. Incluso el mismo Rey del Bosque o hasta el pensamiento del espantapájaros -; b) el trazo se presenta más trabajado, con un trabajo de color y entintado más preciso, favorecido y hasta obligado por la ampliación de la viñeta. En la segunda tira, el contraste entre el esquematismo y el realismo de la foto colocada como fondo e improbable portal dislocan el sentido de lo real. He aquí un guiño del autor, quien utiliza la que se presenta como su voz más regular - si bien el autor es todos sus personajes, el Rey del Bosque es sin dudas su autor -. Ese mundo dentro de otro mundo, como ha sido presentado Edén, toma un sentido literal para revelarnos ese juego de real/irreal y el caos que acecha siempre desde alguna grieta. Sin embargo, el hecho de no abundar el recurso de la sátira/pastiche no implica que Edén sea apolítico o ingenuo. Hay observaciones con implicancias directas a temas como el trabajo y el poder:

Figura 20 - Trabajo
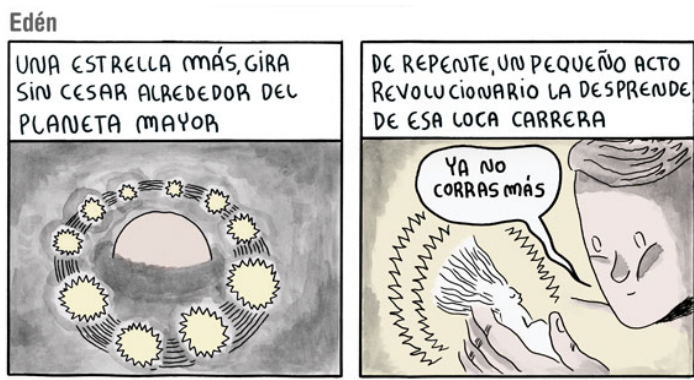

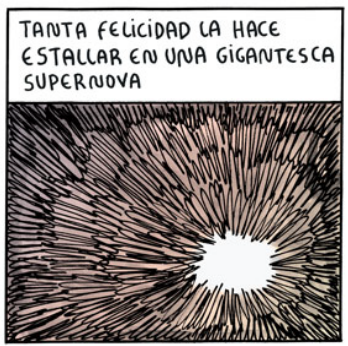

Fonte: Kioskerman (2011)

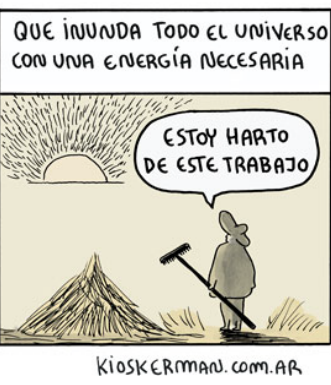

KIOSKERMAN. COM.AR

Figura 21 - Verde
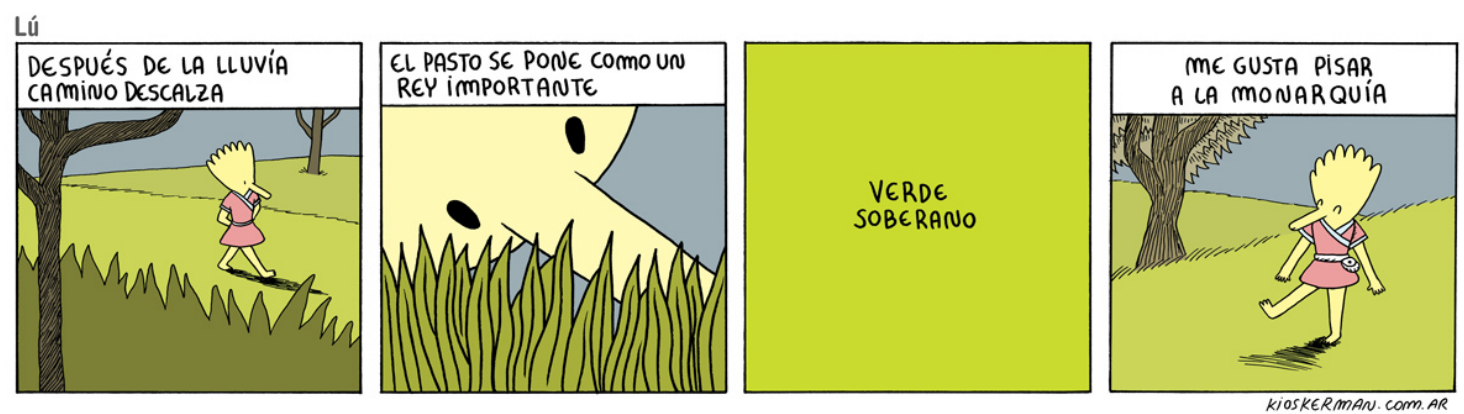

Fonte: Kioskerman (2011) 
Bajo ese esquematismo, se vuelve al relativismo en la primera tira, - Trabajo -; mientras que en la segunda se produce una divertida contradicción: cierto sentido antimonárquico como subversión de las jerarquías naturalizadas mientras que el Rey del Edén es presentado justamente como monarca. Debemos entender esa elección en un contexto de cierta autoparodia - el rey que caminando por su reino al mismo tiempo encuentra sus límites en lo Real -.

Otra dimensión que toma el esquematismo/experimentación de Kioskerman/Holmberg es el que hace al plano pictórico de algunas viñetas. Estas son también excepcionales pero demuestran una dirección hacia un lenguaje postpictórico en desarrollo que promete ser tal vez la mejor revelación de Edén:

Figura 22 - Mudanza
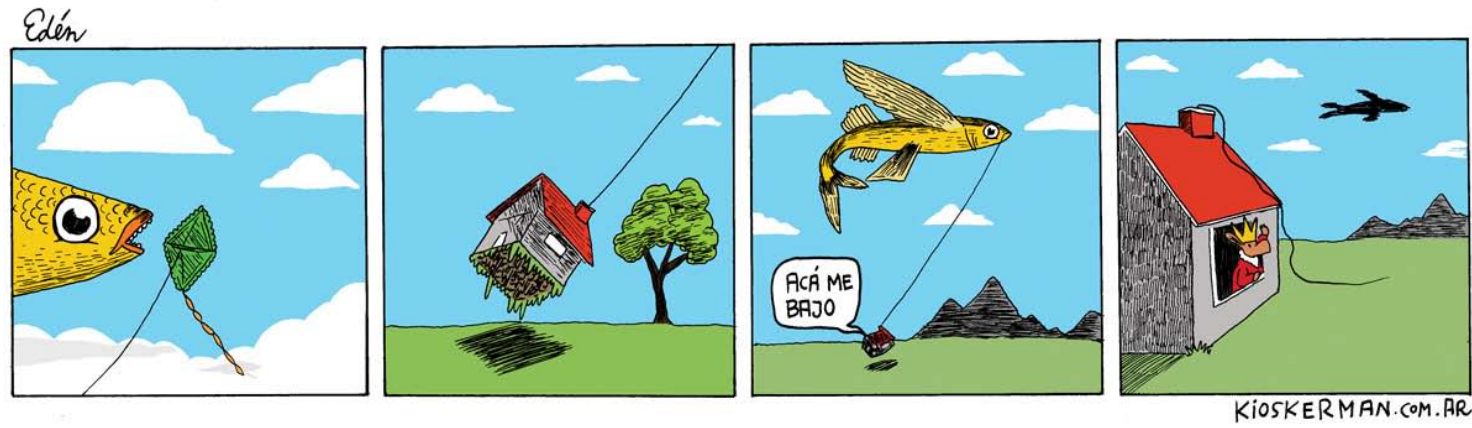

Fonte: Kioskerman (2011)

Figura 23 - Bolas
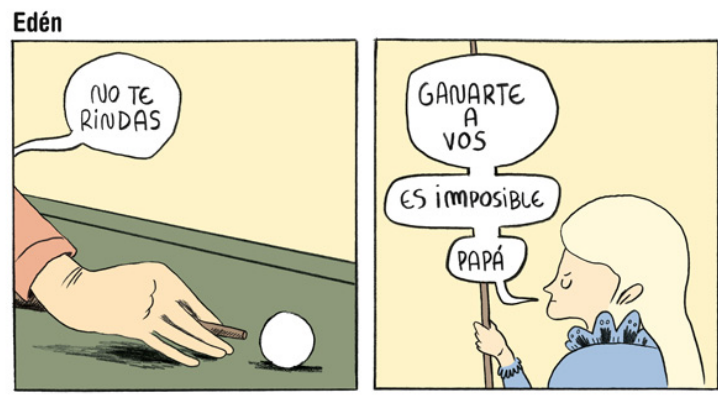

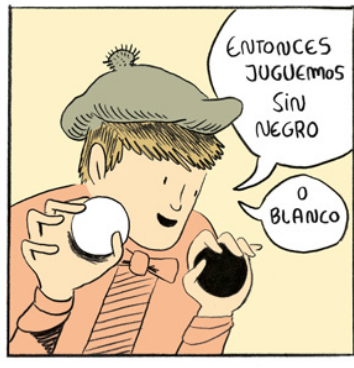

Fonte: Kioskerman (2011)

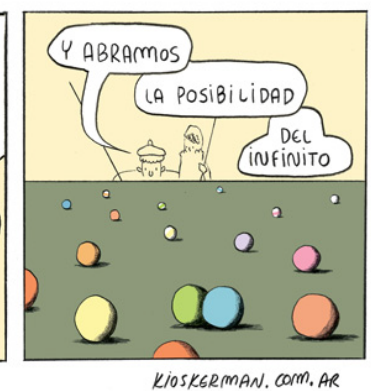

KIOSKGRMAN. COMM. AR 
En ambos hay algo de surrealismo. El primer caso, Mudanza, es más claro. Un pez volador que literalmente vuela arrastrando una casa como si se tratara de un anzuelo, termina siendo un favor amistoso al Rey del Bosque quien se muda de una forma que podría haber sido ideada por cualquiera de los surrealistas, y a quienes les hubiera encantado la idea, como a los dadaístas les fascinaba Krazy Katz. En el segundo caso, Bolas, el despliegue visual de la última viñeta le imprime una potencia que parece alejarse del esquematismo previo, hasta llevarlo a una mera delineación de figuras para darle el primer plano a un escenario de abstraccionismo geométrico que recuerda el uso metafísico del volumen y la perspectiva que realizaran artistas como Escher o De Chirico.

Figura 24 - Juego

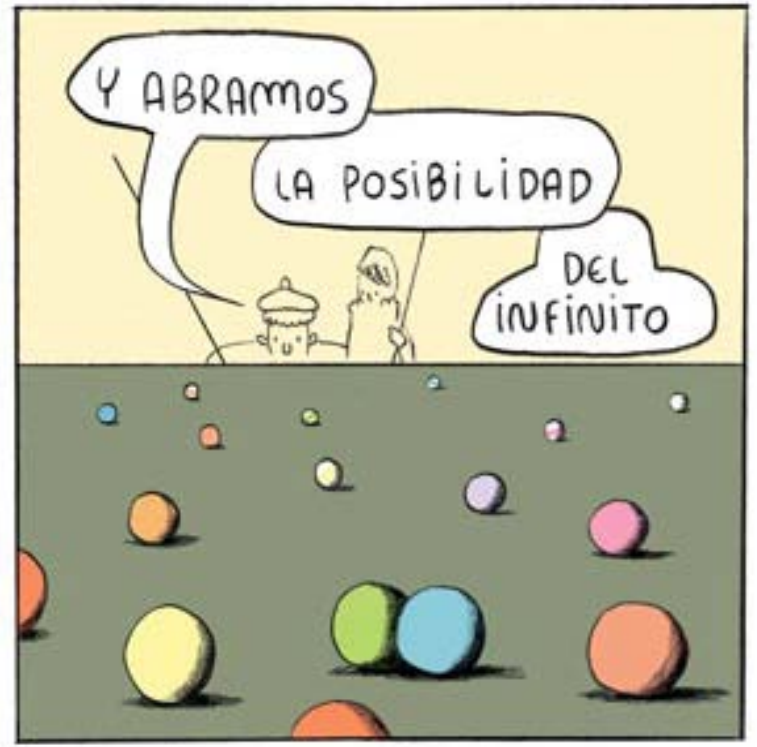

Fonte: Kioskerman (2011)

Esta viñeta que es en sí mismas dos viñetas no solamente juega con la división interna sino que promueve dos estilos completamente diferentes. Ya no está en juego la partición de la unidad del plano, sino la coexistencia entre imagen/palabra pero además la explicitación de la fórmula esquematismo/experimentación, la cual no sólo sostiene su tensión, sino que es gracias a ella que la tira toma otra dimensión. 
Figura 25 - El infinito

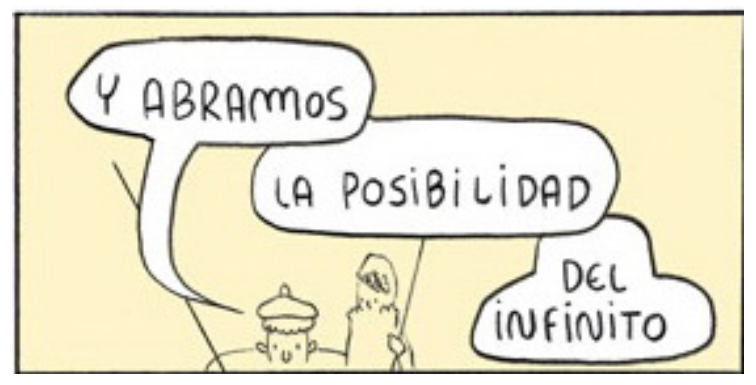

Fonte: Kioskerman (2011)

Los globos de diálogo, superpuestos pero en continuidad, como stacattos, arrastran nuestra mirada a la parte inferior desde donde nos redirigimos al esquematismo de la parte superior por medio del punto de fuga que confluye en dirección a los personajes.

Figura 26 - Formato

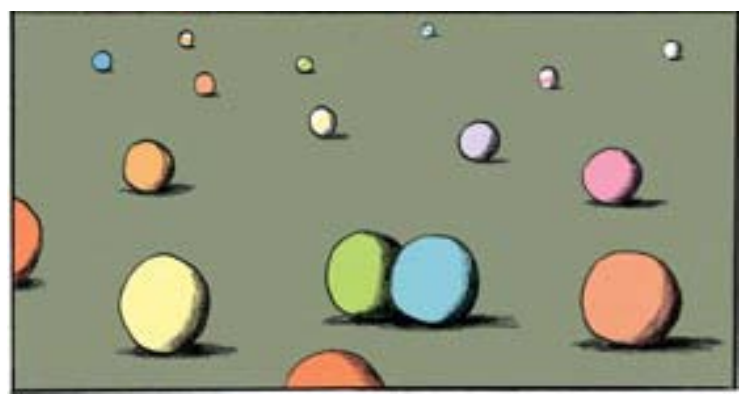

Fonte: Kioskerman (2011)

Resta una pregunta clave: ¿cómo se ve esta lectura afectada por su soporte, su formato? Es notable la diferencia entre las tiras publicadas en las páginas de Kioskerman y la edición en papel antes mencionada. Algunos factores a tener en cuenta: a) la lectura se hace de manera diferente, ya que mientras que en internet la puesta en página es horizontal, en el papel la tira ha sido dividida en dos columnas de dos viñetas cada una. Así, el orden es horizontal/verticaldiagonal/horizontal: 
Figura 27 - Picaflor
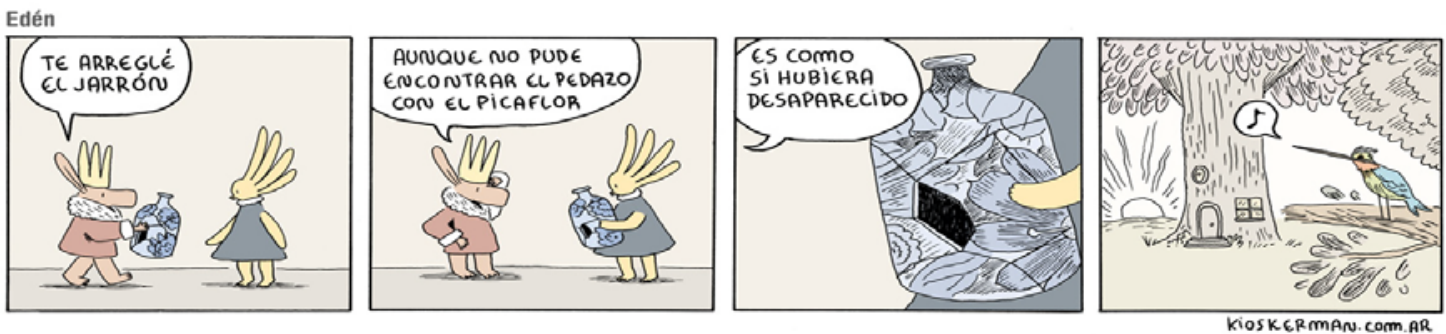

Fonte: Kioskerman (2011)

Figura 28 - Picaflor
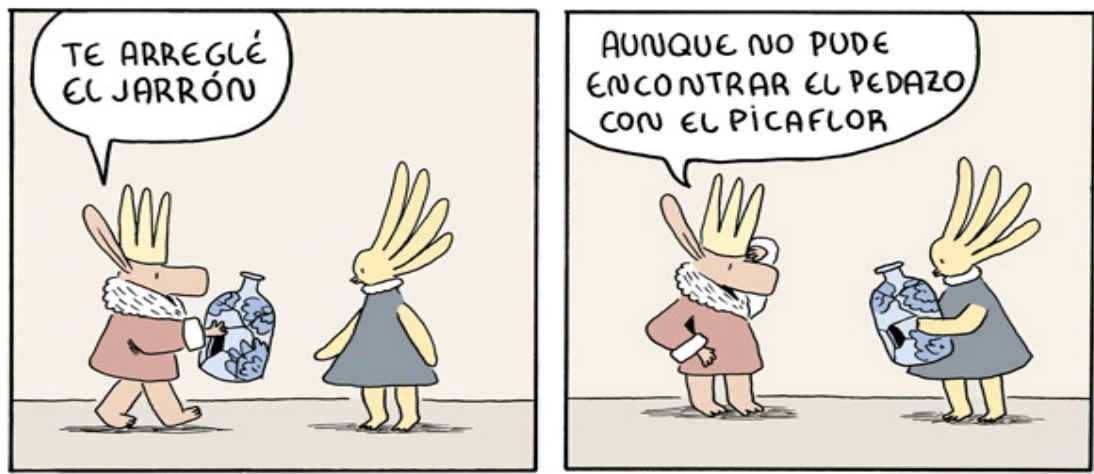

Figura 29 - Picaflor
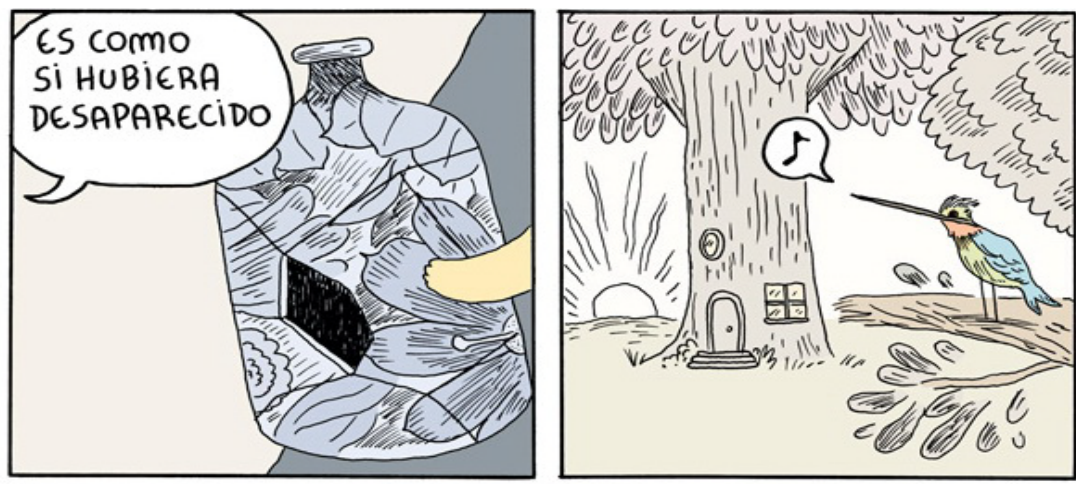
b) el coloreado es diferente. Mientras que la tira de Internet suele sufrir cierto efecto de opacidad que hace demasiado grisácea la paleta - muchas veces de colores fríos, lo cual atenta contra el efecto de calidez del Edén -, en el papel se ha hecho un interesante trabajo donde se rescatan de mejor manera los contrastes de luces y sombras, sin abandonar la paleta ni transformar demasiado la tira; c) el ritmo de lectura cambia al pasar de una página a la otra, ya que entra en juego la visión periférica, neutralizada por el pasaje horizontal y singularizado de la tira digital; d) cierta pauta organizativa/temática ya de por sí algo difícil en una tira como Edén, pero que mantiene cierto registro y ciertas divisiones. La decisión editorial es otra, a diferencia de Internet donde aparecen más bien como algo más azaroso y acumulativo antes que transicional. La cuestión del formato está clara para Kioskerman/Holmberg:

Mi manera de trabajar estuvo influida en muy poca medida por Internet. Yo trabajo pensando en un libro. Internet me sirve mucho porque la tira de cuatro viñetas funciona muy bien. Ya que el lapso de atención en Internet es corto. Pero Internet es solo un medio de difusión. No afecta casi nada mi trabajo. En cambio el libro sí lo afecta. Desde que empecé Edén quise que mis libros se vieran como los de Peanuts, con una grilla que nunca cambia. (RODRIGUEZ, 2011)

Paulo Ramos (2010) también ha abordado el tema:

O cuadrinista argentino [Kioskerman/Holmberg] vê cada bloco de tiras como uma obra e internet como um lugar transitório para se chegar aos livros impressos, a casa que, de fato, pretende habitar.

Y luego, citando al propio autor:

Me sinto parado em uma época em que posso ver, atrás de mim, a tira de jornal como formato diário e, adiante de mim, o romance gráfico como novo cultura de lectura. Gosto de ser um nexo entre os formatos. Sou um pouco filho de ambas as formas e gostaria de poder compor uma síntese, buscar ouvir ambas as vozes, porque as desfruto de maneira igual. (RAMOS, 2010).

Este devenir libro de una tira digital es un sistema que ha dado sus frutos como modelo de producción y publicación de principios del siglo XXI. Resta saber hasta qué punto se complejizará 
- o no - dicha dinámica. Por lo pronto, Kioskermna/Holmberg es un buen ejemplo de un nuevo tipo de autor, o mejor dicho de un sujeto y una manera de encarar el camino autoral en las historietas. Ya se ha anunciado un segundo tomo de la tira publicada en papel, incluso ya pensada para el formato libro. De esta manera, podemos hacer un racconto de algunas cuestiones mencionadas en este breve tratado:

El abandono del sistema de publicación industrial y masivo ha favorecido el uso de internet como herramienta de promoción y auto-publicación, teniendo como resultado la ausencia de controles editoriales pero también de un ingreso fijo para los autores. Existe en el caso de Edén lo que podría llamarse un goce autoral, ya que invierte la lógica del sistema productivo de la historieta: la publicación es un fin último, un objetivo a alcanzar pero no está sobreentendida, puede también no darse. Esto es incomprensible para una lógica industrial, ya que se produce para publicar, y por lo tanto para cobrar por lo producido según estándares preestablecidos - cantidad de páginas, de imágenes, de palabras -. Internet permite primero ganar un espacio con una presencia regular, y cierto capital simbólico al circular entre lectores y colegas; eso, de tener la posibilidad, se capitaliza para devenir publicación. También la imagen del mismo historietista con respecto a su tarea ha cambiado y se valora desde otra perspectiva, a menudo en diálogo con ese mundo industrial del trabajo asalariado.

El paulatino pasaje de la tira digital al libro ha transformado y puesto en primer plano la figura de un autor no-literario, ni siquiera de un autor humorista gráfico como los ejemplos más conocidos e instalados como paradigmas (Quino, Fontanarrosa, Caloi).

El pasaje al formato libro - al menos como aspiración - ha favorecido el recurso del esquematismo/experimentación desarrollado por Oscar Steimberg frente a la sátira/pastiche, más frecuente y presente en las ediciones impresas masivas.

El humor gráfico ya no puede entenderse en los mismos términos - incluso hasta poniendo en duda si se trata de humor gráfico en referencia al paradigma autoral clásico -, ya que por un lado no funciona necesariamente como tira impresa, o al menos no encuentra su fuerte en esa instancia; hay una utilización de recursos conceptuales que mezclan referencias pop a la alta cultura, desde la poesía, la pintura, la música, la literatura y por supuesto, también la historieta. 
Esta nueva conceptualización acerca por momentos el humor gráfico a la historieta - que hasta ahora han mantenido cierta distancia, respetuosa pero algo estricta -, sobre todo en el trabajo entre imagen y palabra pero también en la aproximación a tiras donde se experimenta con el no-humor y el no-personaje. Es decir, un lenguaje gráfico más cercano a cierta cadencia poética antes que a un efecto basado en un modelo construido durante décadas al calor de una industria editorial tendiente a la estandarización de los sentidos de la lectura.

La relación entre autor y lector, que puede ser llevada también al plano de la anulación de la distancia entre sujeto y objeto. Al no haber intermediarios, los términos del contrato de lectura cambian. Se verifica entonces un cierto desajuste de un sentir de lectura dado por una comunicación distinta, a menudo más directa pero también por la relación establecida con el soporte/dispositivo de publicación. Estamos antes nuevas formas de lecturas, y esto implica otro compromiso de esos cuerpos lectores, que deben desafiarse a sí mismos a la hora de construir una aproximación nueva a ese objeto al que ahora se enfrentan, en búsqueda de su sentido.

Finalmente, cierto sentido de incertidumbre que trae riesgos y nuevas oportunidades. Es interesante ver cómo el circuito historietístico en la Argentina ya no respeta divisiones tajantes rémora de la organización y división del trabajo -, y cierto zeitgeist hace que la confluencia y el trasvase entre los círculos de autores gráficos - elijan el modo y los recursos que cada uno prefiera -, creen redes donde antes no las había, o las había de otro modo y en otros términos. Cabe preguntarse qué lugar podría caberle a la crítica no ya como mera crónica, sino como posibilidad de creación conceptual que construya puntos de encuentros, verdaderos nodos donde verificar las transformaciones de un medio y un lenguaje de múltiples dimensiones que recién parece estar empezando a ganar conciencia de sus posibilidades. La historieta no sólo como objeto cultura, sino como transformación de las condiciones de producción en un momento donde el reacomodamiento de las fuerzas creativas coincide con un reacomodamiento del capital expresado en la industria editorial.

Figura 30 - Vela
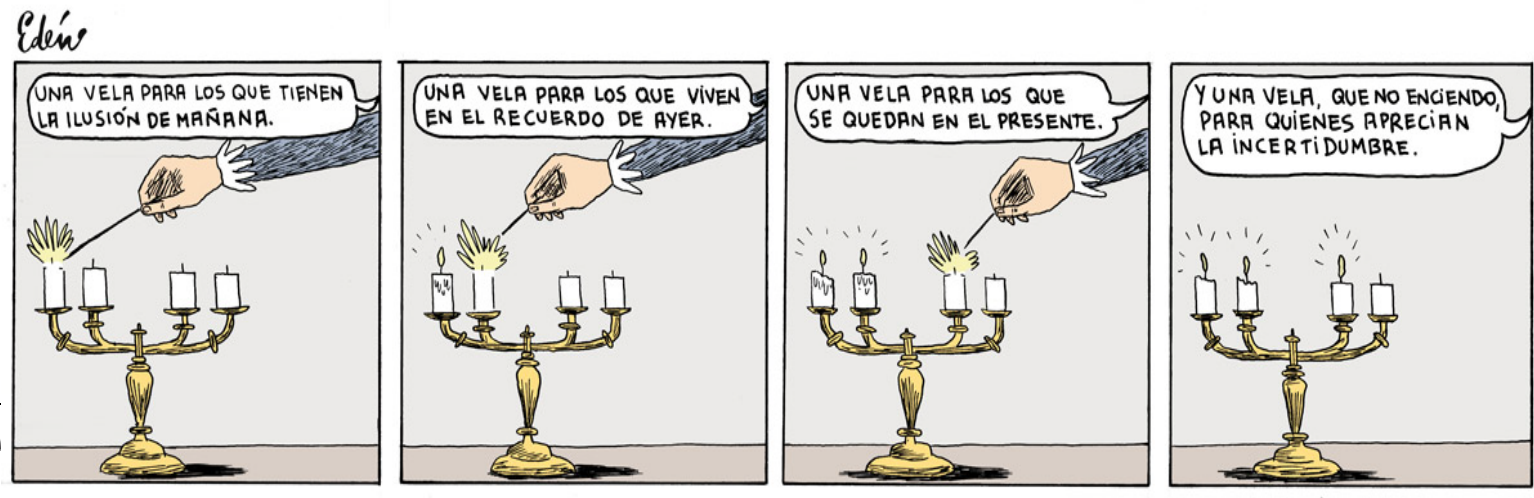
Fonte: Kioskerman (2011)

\section{Referências}

BERGER, Peter. Risa Redentora: la dimensión cómica de la experiencia humana. Barcelona: Kairós, 1999.

BERGSON, Henri. La Risa. Buenos Aires: Losada, 2003.

FREUD, Sigmund. El chiste y su relación con lo inconciente. In: . Obras completas. Buenos Aires: Amorrortu, 2004. t. 8.

FREUD, Sigmund. El Humor. In: . Obras completas. Buenos Aires: Amorrortu, 1979. t. 21.

HOLMBERG, Pablo. Entrevista a Kioskerman. 2007. Disponible en: <http://carboncito.blogspot.com.br/search?q=Pablo+Holmberg>. Acceso en: 14 mayo 2007.

JIMÉNEZ, Jesús. 'Edén', un cómic argentino que triunfa en Internet. 2011. Disponible en: < http://www.rtve.es/noticias/20110208/eden-comic-argentino-que-triunfa-internet/ 402357.shtml>. Acceso en: 8 Feb. 2011.

KIOSKERMAN. Edén. Buenos Aires: Sudamericana, 2009.

KIOSKERMAN. El Señor de el Kiosco como a Edén. Disponible en: $<$ http://www.kioskerman.com.ar>. Acceso en: jun. 2011.

RAMOS, Paulo. Bienvenido: um passeio pelos quadrinhos argentinos. Campinas: Zarabatana Books, 2010.

REGGIANI, Federico. La gran llanura de los chistes. Hablando del Asunto, Buenos Aires. Disponible en: <http://www.hablandodelasunto.com.ar>. Acceso en: 6 de Nov. de 2009.

REGGIANI, Federico. Prosas profanas, versos sencillos. Hablando del Asunto, Buenos Aires. Disponible en: <http://www.hablandodelasunto.com.ar>. Acceso en: 13 nov. 2009.

RODRIGUEZ, Diogo. Caos no Éden: misturando ramantismo e filosofia, cartonista argentino Kioskerman lança livro no Brasil. Disponible en: <http://revistatrip.uol.com.br/so-nosite/entrevistas/caos-no-Eden.html>. Acceso en: 2 Fev. 2011.

STEIMBERG, Oscar. Sobre el análisis del humor gráfico. Signo y Seña, Buenos Aires, n. 12, p. 99-118, 2001. 
VALENZUELA, Andrés. Kioskerman, silencio y poesía en viñetas. 2010. Disponible en: $<$ http://avcomics.wordpress.com/2010/05/02/4462/>. Acceso en: 2 mayo 2010.

Recebido em 30/02/2012

Aprovado em 30/05/2012 